\title{
El balneario de Fortuna y la Cueva Negra (Fortuna, Murcia)
}

\author{
Antonino Gonzalez Blanco * \\ Manuel Amante Sánchez * \\ PH. RAHTZ \\ L. WATTS
}

\section{TERMALISMO EN LA REGIÓN DE MURCIA}

La complejidad geológica de la región de Murcia hace que los acuíferos existentes en ella estén muy compartimentados y relacionados a través de grandes fracturas, que ponen en contacto los almacenes de aguas termales con acuíferos superficiales que no son otra cosa que un camino hacia la emergencia natural. Esta peculiar configuración geológica convierte a la región del Sureste en una zona particularmente propensa a exteriorizaciones geotérmicas, una de cuyas manifestaciones es el termalismo ${ }^{\prime}$.

$Y$ en efecto el termalismo en Murcia es un fenómeno de una importancia grande. A juzgar por la bibliografía hidrológico-médica española ${ }^{2}$,

\footnotetext{
* Universidad de Murcia.

- Fernández GutiérRez, J. C., «Síntesis geológica del SE españo|», Historia de Cartagena, Murcia 1986, vol. I, págs. 47-112. Para una visión general del estado de la investigación sobre termalismo y geología de la Península lbérica en este mismo congreso MaRTín EscoRZA, C., «La estructura geológica de la Península lbérica y sus aguas termales».

${ }^{2}$ Hemos utilizado especialmente la obra de MARTínez Reguera, Bibliografía hidrológicomédica española. Madrid 1896.
} 
los nombres de Fortuna $^{3}$, Archena ${ }^{4}$, Baños de San José ${ }^{5}$, Mula ${ }^{6}$, Gilico $^{7}$, Alhama ${ }^{8}$, Cartagena ${ }^{9}$, Mazarrón ${ }^{10}$, Carraclaca ${ }^{11}$ o La Fuensanta ${ }^{12}$ son un elenco incompleto pero aproximado de la abundancia y calidad de sus aguas medicinales calientes (fig. 1).

\section{LA TRADICIÓN Y LA ARQUEOLOGÍA}

A pesar de toda esta tradición termal y del espléndido documento que constituye la lápida de los duumviros de Archena ${ }^{13}$, y a pesar de que

\footnotetext{
${ }^{3}$ Limón Montero, A., Espejo cristalino de las aguas de España, hermoseado y guarnecido, con el marco de variedad de fuentes y baños, cuyas virtudes excelencias y propiedades se examinan y disputan y acomodan a la salud, provecho y conveniencia de la vida humana. Alcalá de Henares 1697, Libro II, cap. 13, págs. 321-324; Gómez de Bedora y PARedes, P., Historia Universal de las fuentes minerales de España, sitios en que se hallan, principios de que constan, analisis, y virtudes de sus aguas, modo de administrarlas, y de ocurrir a los accidentes, que suelen nacer de su abuso; todo deducido de la observación, y experiencia; descripción de los lugares de su situación, con buena parte de la Historia natural del término de cada pueblo, y la explicación de las curiosidades que contiene, Tomo segundo que comprende las letras C.D.E y F. Santiago de Compostela 1765, págs. 340-345; en 1819 era director el Dr. Samartín; existe una instancia de don Juan Carrión pidiendo la dirección interina, acompañando una certificación recomendatoria del Ayuntamiento de Orihuela, de donde es médico titular. Consta en el expediente que por Real Orden de 20 de abril de 1835 se suprimió esta dirección a indicaciones del gabernador civil, y que por otra Real Orden de 7 de mayo de 1836 se autorizó al titular de dicha villa don Pedro lbáñez, para asistir a los bañistas por la retribución voluntaria de estos (cfr. MARTinez Reguera, L., Bibliografía hidrológico-médica española. Madrid 1892, pág. 128); "Breve noticia sobre las aguas minero-medicinales de Fortuna (Murcia)», El Siglo Médico, n. ${ }^{\circ} 378,31$ de marzo de 1861 (con indicaciones terapéuticas y la cita del análisis efectuado en 1843 y 1847 por los señores don Manuel Baquero y don Vicente López, farmacéutico de Orihuela); Baños de Fortuna (sin portada con el titulo a la cabeza del texto, el cual en cuatro hojas, sin foliatura, expone los materiales que el autor ha reunido para formar una monografia que tenía el propósito de dar a luz y que promete editar en la próxima temporada) está firmado en Abanilla a 12 de diciembre de 1862; Memorias sobre los baños de Fortuna. Año 1864 (una hoja de portada y 42 de texto, firmado en Abanilla el 12 de enero de 1865 por José Chacel. Contiene la reseña histórica del establecimiento, sus recientes mejoras, descripción física, química y medicinal de las aguas, exponiendo el análisis realizado en 1863 por don Antonio Hernández Ros y con historias nosológicas notables); Breve noticia sobre los baños termales de Fortuna en la provincia de Murcia. Murcia 1864 ( en 4, ocho páginas, sin portada; el texto está firmado en Baños de Fortuna, 30 de junio de 1864. El médico director José Chacel; plano en tela, a cinco tintas, de los nuevos baños de Fortuna, fechado en Murcia 26 de agosto de 1868); Dirección médica de los Baños de Fortuna (sucinta memoria de dos hojas en folio, sin portada ni título, fechada en Fortuna 20 de Diciembre de 1869, relativa a aquella temporada); Baños de Fortuna. Año 1871 (una hoja de portada y 13 de texto sin numeración: encabezado con el epígrafe "Memoria de los Baños minerales de Fortuna» y
} 


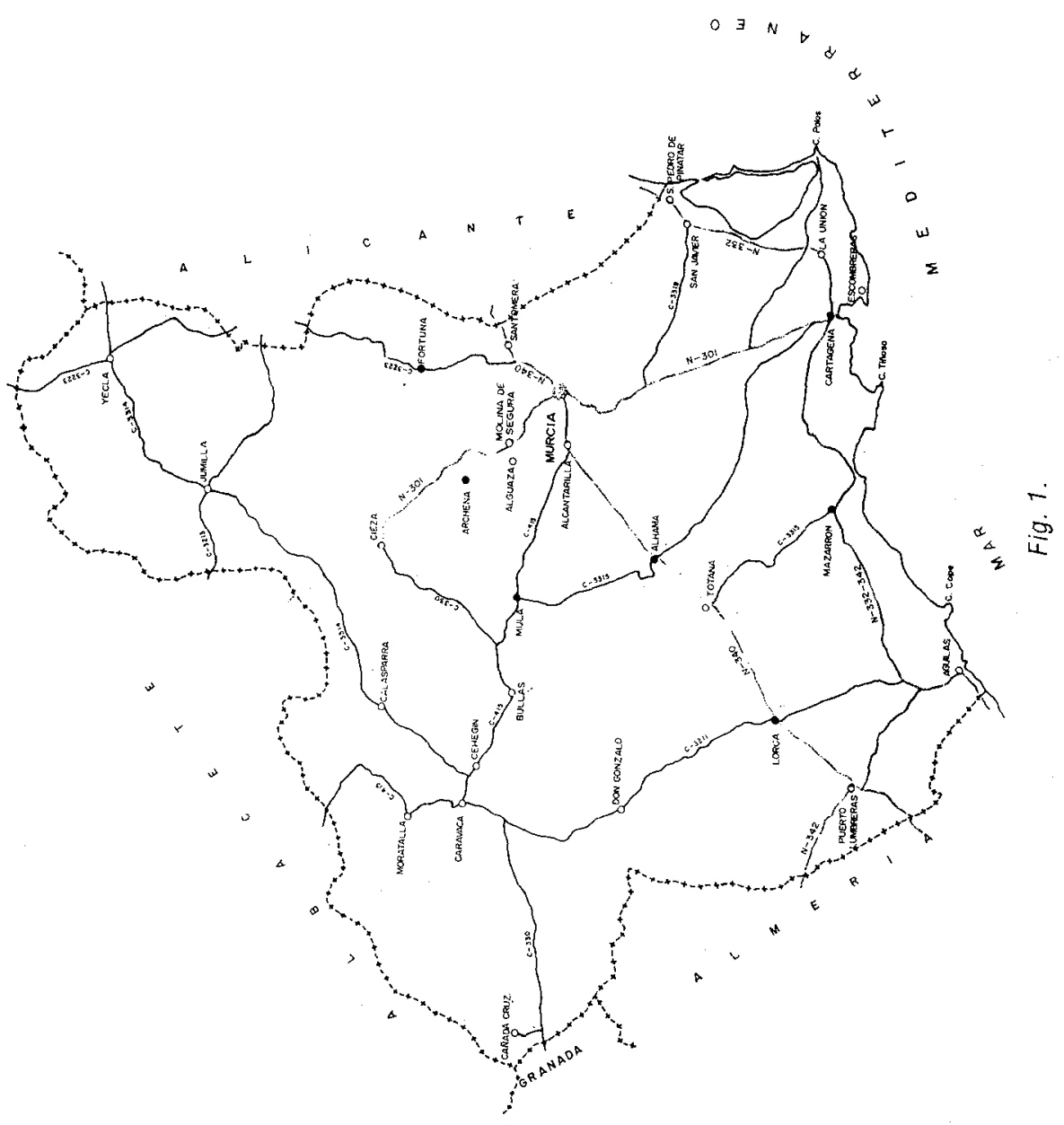


habia habido indicios de uso antiguo de las aguas termales ${ }^{14}$, el problema de la dimensión urbana y civica de las fuentes termales no habia sido tratado con suficiente relieve por la historiografía ni general ni local. Probablemente porque el nivel de conocimiento en el campo de la historia antigua era bajo y sólo recientemente ha comenzado a plantearse con

firmado en Orihuela a 1 de diciembre de 1871 por Juan Carrić Grifol, informa sobre el establecimiento y los análisis de sus aguas realizados por el Dr. Garagarza y cuadro estadístico de aquella temporada); Breve Memoria de los Baños de Fortuna. Año 1872 (dos páginas de portada y 24 de texto con cuadro estadístico-clinico de la segunda temporada de 1872. Se ocupa de la descripción del establecimiento, sus aguas y aplicaciones. Firmado en Madrid a 16 de diciembre de 1872. El médico-director, Eduardo Aragón Ovejero); en 1876 era director el Dr. Arnús de Fortuny; Aguas y baños termales de Fortuna de Juan Cascales y Font. Barcelona 1876 (portada con una lámina representando a la Fortuna sobre su alegórica rueda, debajo de la cual brota un caudaloso manantial, a cuyos lados hay dos huertanos de Murcia, el hombre de pie y la mujer sentada con una cántara en la mano izquierda; trata de la descripción del establecimiento, análisis de Dr. Garagarza, acción terapéutica, indicaciones, itinerario, etc.); en 1877 era director en comisión el Dr. Chacel; el 13 de junio de 1879 entra de director por permuta el Dr. Masó; Memoria médica de las aguas de Fortuna. Año 1879 ( $\sin$ portada, con 16 hojas de texto: expone la situación de estos baños, propiedades físicas del agua, comparación de las aguas de Fortuna con otras similares de España y del extranjero y su clasificación oficial. Efectos de las aguas si se beben, si uno se baña. Enfermedades que se combaten con estas aguas. Contraindicaciones. Tratamientos, etc. Fechado en baños de Fortuna a 31 de octubre de 1879. Médico-director Juan Grau); en el mismo año de 1879 y en Barcelona se publica la Hidrología médica de Fortuna obra de A. Maso Bru y M. Arnus Fortunyen; 1880 es director el Dr. López Díez; ese mismo año de 1880 es director en comisión el Dr. Carabias; en 1881 es director el Dr. Calderón; en 1885 es director el Dr. Lacort que un año más tarde escribirá su Estudio razonado del agua mineromedicinal del balneario de Fortuna publicado en Barcelona y reeditado en 1991; Otras obras más recientes sobre Fortuna y su balneario son las debidas a $S$. Alonso Navarro ¿Conoce usted Fortuna? publicada en 1966, y El libro de Fortuna publicado en 1973 y los Estudios sobre el Balneario de Fortuna, por los doctores J. M. López de Azcona, M. C. de la Rosa, M. A. Mosso, F. Díaz, J. A. Castellanos, M. L. Garcia Arribas, P. Garcia Puertas, M. E. Torrija Isasa, M. T. Orzaez Villanueva, F. Plaza Piñol, R. Vela Guillén, J. L. Alias y J. Gómez de las Heras. Instituto de España. Real Academia de Farmacia. Memoria ${ }^{\circ}{ }^{\circ} 13$. Madrid 1987.

${ }^{4}$ LIMON MONTERo, A., Op. cit., Libro II, cap. 12, págs. 318-321; hay una carta fechada el 14 de diciembre de 1751 del boticario de la villa de Yecla y visitador de boticas del Reino de Murcia, Antonio Castaño y Ruiz de Bedoya que alude a hallazgos arqueológicos en Archena; CERDAN, F., Disertación físico-médica de las virtudes medicinales, uso y abuso de las Aguas thermales de la villa de Archena. Murcia 1760; Gómez de Bedoya y Paredes, P., Historia Universal de las fuentes medicinales de España..., págs. 257-265; LóPEZ de AyALA, l., Poema phisico de los Baños calientes de la villa de Archena en el reyno de Murcia. Murcia 1777; BREIX, J., Disertación histórica, física, analitica, medicinal, moral y metódica de las aguas thermopotables de la villa de Archena. Reyno de Murcia. Cartagena 1801; AlIx, J., Memoria sobre las aguas medicinales de Archena. Murcia 1818; De 1825 a 1829 fue director del balneario en comisión el Dr. Samartín; en 1829 fue director el Dr. Rubio; en 1836 consta que fue director el Dr. Sánchez de las Matas; Sobre las aguas de Archena (oficio de seis páginas manuscrito de la dirección balnearia, firmado en Baños de Archena a 16 de octubre de 1838 por Nicolás Sánchez de las Matas, dando cuenta entre otras cosas de la inundación de los baños por la avenida del Segura ocurrida a las doce de la noche del 3 de octubre; Año de 1838. Memoria sobre los efectos de las aguas minerales de Archena, conforme al artículo 


\section{El balneario de Fortuna y la Cueva Negra (Fortuna, Murcia)}

fuerza todo lo que tiene que ver con el urbanismo y los usos cívicos. En la base del problema probablemente está el hecho muy conocido del silencio de la epigrafía del Se peninsular en lo que a nombres de dioses prerromanos se refiere: a diferencia de lo que ocurre en otras áreas donde está muy bien documentada la existencia de divinidades de las aguas

37 del Reglamento del ramo. Por don Nicolás Sánchez de las Matas, médico-director del establecimiento (con historias clínicas y problemas sobre la propiedad del balneario); SÁNCHEZ DE LAS MATAS, N., Memoria sobre los efectos de los baños y aguas minerales de Archena. Madrid 1846; Memoria correspondiente al año actual. Por don Nicolás Sánchez de las Matas. Médico-director por S.M. de dicho establecimiento. Año 1863 (una hoja de portada y 34 de texto, con información médica); Memoria de Reglamento sobre los Baños y aguas minerales de Archena. Años de 1886. Por don Nicolás Sánchez de las Matas. Médico-director por S.M. del mencionado establecimiento (una hoja de portada y 105 de texto); Memoria sobre los baños y aguas minerales de Archena, por don Nicolás Sánchez de las Matas, Doctor en Medicina y Cirugia: del gremio y claustro de la Universidad de Salamanca; excatedrático y Decano de la Facultad de Filosofía de la misma; socio de la Academia Lineana, de Ciencias Físicas y Químicas de París; Médico Director por S.M. del referido establecimiento, etc. Madrid 1867 (viene a ser una segunda edición de la memoria escrita en 1846, corregida y aumentada); en 1869 era director el Dr. Medina; en 1874 lo era el Dr. Zabala; ZaBalA, J. M., Aguas minero-medicinales de Archena. Madrid 1875; Memoria sobre las aguas minerales de Archena correspondiente a el año 1877. Provincia de Murcia (una hoja de portada y 21 de texto); Guia del bañista en Archena por un bañista. Sevilla 1881; en 1884 era director por permuta el Dr. Quesada; en 1886 era director por permuta el Dr. Taboada; en 1887 lo era el Dr. Lletget; Baños minero-medicinales de Archena. Barcelona 1888 (una hoja de portada y cuatro de texto sin foliar: expone la reforma introducida en aquella temporada con la sala de inhalación y el resultado de las operaciones metereológicas); en 1890 era director el Dr. Zavala; en 1892-93 era director por permuta el Dr. Calvo; Informe sobre los baños de Archena en 1892 (sin portada ni titulo, con 2 hojas de texto, suscrito en Madrid a 31 de diciembre de 1892: cumple el trámite alegando la imposibilidad de escribir algo más serio con la observación de una sola temporada); en 1894 era director por permuta el Dr. Calvo; en 1895 era director del Dr. Garcia López; en 1895-96 fue director por permuta el Dr. Garcia López; Valle Montero, M., Algunos datos para la futura historia de Archena. Murcia 1949; Estudio sobre el Balneario de Archena, por los doctores J. M. López de Azcona, M. A. Mosso, F. Diaz, M. C. de la Rosa, P. García Puertas, M. E. Torija Isasa, M. T. Orzaez Villanueva, F. Plaza Piñol, I. Aguayo Martos y Luis J. Alias Pérez. Instituto de España. Real Academia de Farmacia. Memoria n. ${ }^{\circ}$ 12. Madrid, 1986; Medina Tornero, M. E., Historia de Archena. Murcia 1990.

${ }^{5}$ Sólo tenemos el indicio del topónimo situado con señal y nombre en la carretera en el paraje llamado «Cagitán», entre Cieza y Mula.

${ }^{6}$ Existe una instancia de don Vicente Carlet y Font, subdelegado de Medicina y Cirugía de Villena, solicitando la dirección de los baños termales de Mula. Con informe de la Diputación provincial de Murcia 1837, diciendo que, aunque los baños de Fortuna, Alhama y Mula no son tan famosos como los de Archena, no dejan de producir buenos resultados, por to que convendría dotarlos de médico-director, o, de no ser esto posible, encomendarlos a los facultativos de los pueblos más inmediatos. Se le concedió la interinidad el 15 de junio de 1844 (cfr. Martinez Reguera, L., Bibliografía hidrológico-médica española, pág. 128). Además, ZuÑIGA, I., «Los Baños de Mula pueden desaparecer». Diario Línea, 1980.

${ }^{7}$ Hay tradición de usos balneares, pero no hay literatura, que conozcamos, al respecto.

${ }^{8}$ Gómez de Bedoya y Paredes, P., Historia Universal de las fuentes minerales de España... Tomo primero que comprende las letras A y B, Santiago de Compostela 1765, págs. 218 y 
y de otras muchas, el silencio acerca de la conciencia religiosa prerromana o indigena de época romana es exasperante. Sea de ello lo que

s; Baños minero-medicinales de Alhama Murcia. Observaciones prácticas. Correspondientes a las dos temporadas del año 1848. Por su actual director (una hoja de portada y 14 de texto con 17 historias clínicas); Resumen práctico, $u$ observaciones recogidas en las dos temporadas en que se usan las aguas Thermo-medicinales del Manantial de la villa de Alhama, provincia de Murcia, correspondientes al año corriente de 1863: por su Director facultativo don José María del Castillo Espinosa de los Monteros (una hoja de portada y 14 de texto); Apuntes prácticos, correspondientes a las observaciones recogidas durante dos temporadas del presente año de 1864, en los baños thermo-medicinales de la Villa de Alhama, provincia de Murcia, por su director José Maria del Castillo (once hojas); Memoria sobre las observaciones prácticas recogidas en el Establecimiento de los baños thermo-medicinales de la villa de Alhama, provincia de Murcia, durante las Temporadas del uso de sus aguas en el presente año de 1865 por su director don José Maria del Castillo (una hoja de portada y siete de texto); Establecimiento de baños y aguas minerales de Alhama, provincia de Murcia. Memoria que en cumplimiento al párrafo 9 del art. 57 del vigente reglamento de baños y aguas minerales eleva a la Dirección General de Beneficencia y Sanidad, don Francisco Chinchilla y Ruiz, Médico Director de Establecimientos balnearios. Año 1887 (una hoja de portada orlada y 13 de texto sin numerar. Publicada por la Dirección General en el n. ${ }^{\circ}$ del tomo II del Boletín de Sanidad, del Ministerio, págs. 205-210 el 30 de septiembre de 1888 con el título de «Baños de Alhama de Murcia. memoria del Director correspondiente al año 1887 "); Establecimiento de baños y aguas minerales. Alhama. Provincia de Murcia. Memoria que en cumplimiento al párrafo 9 del art. 57 del vigente reglamento de baños y aguas minero-medicinales eleva a la Dirección General de Beneficencia y Sanidad don Francisco Chinchilla y Ruiz, Médico Director del Establecimiento de Baños. Año de 1892 (una hoja de portada orlada y 10 de texto sin numerar: estado de los manantiales; mejoras llevadas a efecto y proyectadas; mejoras de urgente necesidad...); Hay otra memoria de 1896 firmada por Pérez Bernabeu. J. Baños Serrano, don Munuera Marín, J. A. Ramirez Águila, «Aprovechamiento agrícola de aguas termales en Alhama de Murcia. Captación, transporte y almacenaje", en El agua en las zonas áridas: arqueologia e historia. Almeria 1989, vol II, págs. 523-542.

${ }^{9}$ LIMÓN MONTERo, A., Op. cit., fol. 190.

${ }^{10}$ En el término municipal de Mazarrón hay pozos de aguas termales, alguno recientemente descubierto y no sabemos que haya sido usado con fines medicinales.

${ }^{11}$ SALA JuST, J., Mi botica. Historia de una farmacia y su entorno sanitario. Lorca 1977. "Balnearios de aguas minero-medicinales", págs. 105- 109; “Los baños de Carraclaca, abandonados", Diario La Verdad, 24-8-1983.

${ }^{12}$ Memoria sobre las Aguas Minerales de Fuensanta de Lorca. Escrita por don Pedro Orozco y Riera, Dr. en Medicina y Cirugia, Socio de número de la Academia Médico-Quirúrgica Matritense. Almería 1863 (consigna el análisis practicado en 1862 por don Juan González Caro y supone, por indicios arqueológicos, que este balneario es el llamado «de la Sultana” por los árabes. Reiteradamiente citado, elogiado y copiado a grandes párrafos por el Dr. Negro en su Monografía, tiene este trabajo, entre otros méritos, el de ser el primero que acerca de estos baños se ha escrito); en 1877 es director el Dr. Nuñez (cfr. Martinez Reguera, L., Op. cit. índice).

${ }^{13}$ Se han encontrado dos lápidas: C.I.L. II, 3542 y 3541 ; esta segunda es la que habla de la traída de aguas por disposición de los duumviros. Cfr. MORA, G., "Las termas romanas en Hispania", $A E s p A, 143-144,1981$, págs. 37 y ss, n. ${ }^{\circ} 75$, pág 54; más bibliografía en MedinA Tornero, M. E., Historia de Archena. Murcia 1990, págs. 82-84.

${ }_{14}$ Hay varios documentos de los que hemos transcrito en la bibliografía de las notas 3 a 11 y algunos los citamos más abajo al hablar de la excavación. 
fuere, lo cierto es que el interés por el uso histórico de las fuentes termales y su importancia ha saltado a unas cotas muy altas de interés por los trabajos arqueológicos en algunos lugares como es el caso de Alhama de Murcia, y para nosotros por los trabajos epigráficos y arqueológicos llevados a cabo en el entorno del balneario de Fortuna ${ }^{15}$.

\section{EL DESCUBRIMIENTO DE LA EPIGRAFIA DE LA CUEVA NEGRA}

Lo hemos relatado ya en otras publicaciones y no vamos a insistir en ello. En 1981 fuimos advertidos de la existencia de epigrafía latina pintada en el techo de la cueva. Tras laboriosos estudios realizados en equipo hemos podido dar a conocer hasta unos 25 epígrafes de los varios centenares que allí existen con una reproducción fotográfica espléndida de los mismos, cuyo estado de conservación es lamentable.

Asimismo hubimos de confesar nuestra desesperación por ser incapaces de hallar un contexto arqueológico adecuado para explicar semejante abundancia y calidad de textos latinos, poéticos todos, y muchos de ellos de gran inspiración y belleza. Había restos romanos en la jurisdicción de Fortuna, pero no conseguíamos descubrir en ellos una entidad que permitiera teorizar sobre los tituli picti.

La interpretación de los textos constituía así una crux de muy difícil explicación y los tres editores del libro manteniamos posturas diferentes al respecto ${ }^{16}$.

\section{EL HALLAZGO DEL YACIMIENTO ROMANO DEL BALNEARIO DE FORTUNA}

La presencia en el entorno del balneario del matrimonio $\mathrm{Ph}_{\text {. Rahtz y }}$ L. Watt, él catedrático emérito de la Universidad de York en Inglaterra, y

\footnotetext{
${ }^{15}$ "La cueva Negra de Fortuna (Murcia) y sus tituli picti. ¿Un santuario de época romana?", Antigüedad y Cristianismo IV. Murcia 1987, más lo que decimos en la presente comunicación.

${ }^{16}$ A. González Blanco expuso su pensamiento en el estudio literario y religioso de los epigrafes de la cueva, publicado en el volumen citado págs. 271-317; MAYer OLIVE, M., «La pervivencia de cultos púnicos: el documento de la Cueva Negra (Fortuna, Murcia)", L'Africa romana. Atti del VII convegno do studio Sassari, 15-17 diciembre 1989. Sassari 1990, págs. 695-702; Stylow, A., «La Cueva Negra de Fortuna (Murcia). ¿Un santuario púnico?", comunicación presentada al congreso sobre Sociedad y Culto en Occidente celebrado en Tarragona en 1989 y cuyas actas están a punto de aparecer.
} 
ella arqueóloga de profesión y colaboradora con el Prof. Rahtz, quienes habian adquirido un casa junto al Castillico de los Baños, orientó decisivamente la brújula hacia los nuevos derroteros de la investigación. Asentados en los Baños y tras los primeros contactos con nosotros, les hicimos llegar cuanta información poseíamos de la arqueología del entorno y ellos se dedicaron a controlar los lugares con el resultado sorprendente y magnífico del hallazgo del yacimiento. Paseando por el paraje denominado «Los Baños Moros» junto a los dos depósitos que ya habíamos reconocido como romanos, observando un perfil producido por las torrenteras se dieron cuenta de que el material que ofrecia era de primera calidad (engobes rojos gálicos de buena época, marmorata, vidrio y alguna moneda). Nos lo comunicaron y decidimos solicitar y realizar la excavación si se nos concedía el permiso. La información que presentamos hoy aquí procede de las dos primeras campañas de excavaciones llevadas a cabo en los años 1990 y 1991.

\section{EL HALLAZGO DEL YACIMIENTO ARQUEOLÓGICO: LOCALIZACIÓN Y ENTORNO}

El paraje conocido como «Los Baños Moros» se encuentra situado a unos $2.650 \mathrm{~m}$ en línea recta desde la Cueva Negra, en el lado oeste de la carretera que une Fortuna con los Baños, frente a la segunda entrada de estos, a $38^{\circ} 12^{\prime} 36^{\prime \prime}$ de latitud norte y $2^{\circ} 34^{\prime} 20^{\prime \prime}$ de longitud este según el meridiano de Madrid (hoja 832 Fortuna $1 / 50.000$ del I.G.N), y unos 280 metros de altitud sobre el nivel del mar (fig. 2). El yacimiento se extiende a lo largo de una serie de terrazas de abancalamiento que parten de la orilla misma de la carretera con un desnivel medio entre cada una de ellas de $1 \mathrm{~m}$. En el entorno del yacimiento existen una gran cantidad de puntos de interés arqueológico, en los que se constata la ocupación ininterrumpida de la zona desde la Prehistoria ${ }^{17}$. De estos destacan entre otros por su importancia: el Cabezo de la Mesa (Caprés) situado entre la sierra del Corque y la de los Baños, con restos de la edad del bronce; "La Casa Roja», a $260 \mathrm{~m}$ al este de los Baños con materiales que arrancan desde Augusto (T.S.I.) y ocupan todo el siglo । d. C. ${ }^{18}$; Castillejo de

\footnotetext{
17 Matilla Seiquer, G.-Pelegrín García, I., “Contexto arqueológico de la Cueva Negra de Fortuna", en La cueva Negra de Fortuna (Murcia) y sus Tituli Picti. Un santuario de época romana. Antigüedad y Cristianismo IV. Murcia 1987, págs. 109-132.

${ }_{18}$ Matilla Seiquer, G.- Pelegrín Garcia, 1., Op. cit., nota 16, págs. 112-113.
} 


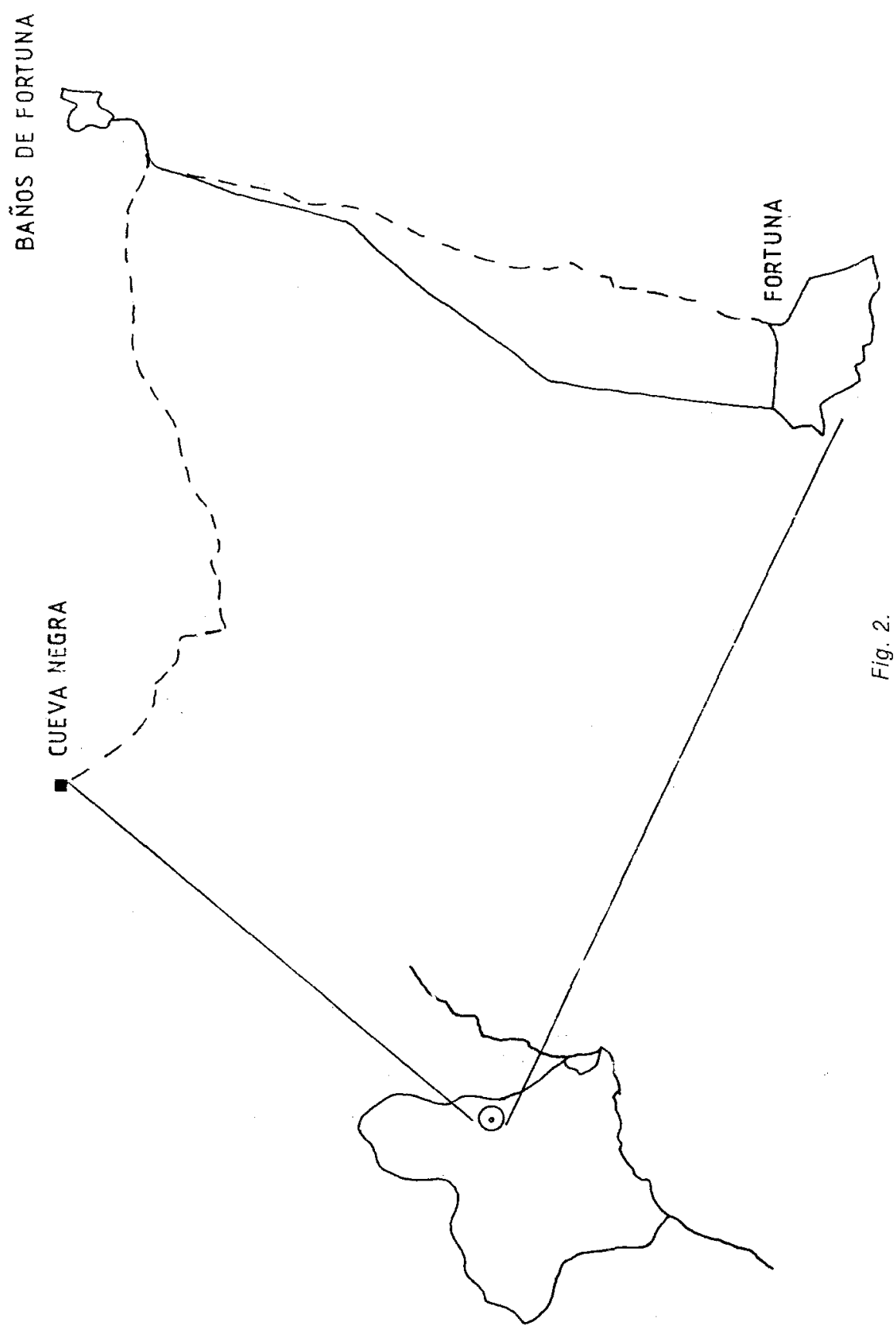


los Baños a unos $500 \mathrm{~m}$ al oeste de la actual estación termal, en donde se encuentran materiales de la edad del bronce, ibéricos ${ }^{19} \mathrm{y}$ barnices negros de los siglos $v$ al IV a. C. ${ }^{20}$; Cueva del Barranco de la Higuera, situada en la ladera noreste de la sierra del Baño, en cuyas excavaciones se ha exhumado abundante material litico ${ }^{21}$; a $4 \mathrm{~km}$ al noroeste de Fortuna en las estribaciones de la Sierra de la Pila se encuentra el yacimiento conocido como Castillico de las Peñas, en el que se localizan restos del bronce medio, época ibérica con presencia de exportaciones de barniz negro y figuras rojas ${ }^{22}$, y época medieval ${ }^{23}$; La Fuente, a $700 \mathrm{~m}$ al norte de Fortuna, ha proporcionado en prospección T.S.G. y producciones africanas en A2; y La Torre Vieja, a 1,6 km al sur de Fortuna, con restos de fortificaciones de clara adscripción medieval ${ }^{24}$.

\section{ANTECEDENTES}

El área objeto de estudio se localiza en la última de las terrazas antes mencionadas, con una superficie total de $1.904 \mathrm{~m}^{2}$. En ella se conservan desde antiguo los restos de dos depósitos para agua de $5 \times 3$ y $5 \times 4$ metros respectivamente, realizados en opus caementicium y recubiertos interiormente de opus signinum rojo, los cuales han sido reutilizados en época moderna presumiblemente para riego, como demuestra la presencia de revestimiento de cemento en sus paredes. La existencia en el yacimiento de instalaciones termales antiguas queda constatada documentalmente en la obra de Agustín Lacort, publicada a finales del siglo XIX, en la que el autor describe una serie de construcciones visibles en su tiempo que él atribuye a época islámica, si bien también apunta la posible existencia de un templo romano anterior, en base a una serie de hallazgos de monedas y esculturas recuperadas en las excavaciones que por aquel entonces realizó Amós Calderón Martínez, médico director del

${ }^{19}$ Lillo Carpio, P. A., El poblamiento ibérico en Murcia. Murcia. Universidad de MurciaAcademia Alfonso $X$ el Sabio, 1981, págs. 338, 345, 362, 371, 375, 378 y 387. 122.

${ }^{20}$ Garcia Cano, J. M., Cerámicas Griegas de la Región de Murcia. Murcia 1982, págs. 115-

21 Matilla Seiquer, G.- Pelegrín Garcia, I., Op. cit., nota 16, págs. 117-118.

${ }^{22}$ García Cano, J. M., Op. cit., nota 19, págs. 123-129.

23 Matilla Selouer, H.-Pelegrin García, Op. cit, nota 16, pág. 119.

${ }^{24}$ Matilla Selquer, G.-Pelegrin Garcia, 1., Op. cit., nota 16, págs. 122-124. 
balneario ${ }^{25}$. A los restos arquitectónicos y muebles mencionados por Lacort (hoy día desaparecidos), se han añadido a lo largo del tiempo una serie de hallazgos casuales que han ido matizando el marco cronológico del yacimiento (cerámicas itálicas, gálicas, africanas, etc.), entre los que destaca un conjunto de denarios encontrado hacia los años cincuenta, encuadrables entre el último cuarto del siglo $n$ y primera mitad del । a. C. ${ }^{26}$

En base a esto, y considerando los Baños como un interesante nexo de unión con la Cueva Negra, en la que se viene trabajando desde marzo de 1981, el Área de Historia Antigua de la Universidad de Murcia decidió en 1990 llevar a cabo excavaciones arqueológicas dirigidas por el Catedrático Dr. González Blanco, y financiadas por la Consejeria de Cultura de la Comunidad Autónoma de la Región de Murcia.

\footnotetext{
${ }^{25}$ LACORT, A., Estudio monográfico razonado del agua minero-medicinal de Fortuna. 1. ${ }^{a}$ edición. Barcelona 1886.

Respecto a las ruinas mencionadas el autor en sus págs. 20-21 dice: «Lo más remoto de que existen pruebas por los fragmentos de obra de fábrica que se han encontrado y restos de escultura de bronce, monedas y otros varios objetos, de los que ha recogido algunos el ilustrado médico-director que ha sido de este balneario, Dr. don Amós Calderón Martínez; en las excavaciones que se han hecho en las inmediaciones y en el sitio en que estaban situados los baños morunos, llamados así porque fueron construidos por ellos durante su dominación en España, en los que por su construcción especial los restos de obras de fábrica, las monedas y los objetos pertenecientes a la época de la dominación romana, hacen creer que en este sitio ha existido tal vez, un templo anterior a los romanos o por lo menos correspondiente a su época, si hemos de creer en las esculturas y medallas encontradas».

«Existia, hasta hace poco, un edificio que construyeron los árabes, rodeado de varias casitas cuya forma de construcción indica también un origen árabe, como casi todas las del mismo barrio.

"El edificio constaba de dos plantas, baja y alta, o mejor dicho, de piso bajo y sótano; el piso bajo estaba dividido en dos departamentos, una especie de portal de entrada tenía comunicación con la planta baja, tal vez para ventilación del baño y gran vaporario.

"Detrás de él había una escalera en rampa de tres tramos para bajar a un sitio que, indudablemente, era un gran vaporario, y que tal vez servía para vestirse y desnudarse, e inmediato al baño, constituido de grandes piedras solamente superpuestas y desiguales, y aunque conociéndose que era de más moderna construcción, cubierto con un techo abovedado".

${ }^{26}$ Amante Sanchez, M.-Lechuga Galindo, M., "Un nuevo hallazgo de denarios romano republicanos en la provincia de Murcia", en NUMISMA, año XXXII, n. ${ }^{\circ}$ 177-179, julio-diciembre 1982. Madrid 1982, págs. 9-20.
} 


\section{PROCESO DE EXCAVACIÓN}

Como trabajo previo se planteó un eje de coordenadas con dirección norte-sur, este-oeste, que reticula la superficie de intervención en cuadrículas de $4 \times 4 \mathrm{~m}$. Al eje norte-sur se le asignaron numeros desde el 1 hasta «n», y al este-oeste letras de la $A$ en adelante. El punto cero ideal se situó sobre la pared noreste del depósito pequeño. En las dos campañas hasta ahora realizadas (1990 y 1991) se ha actuado sobre las cuadrículas F10, E10, G11, F14, E14, H9, G6, y en los depósitos mencionados (fig. 3).

\section{VII.1. Habitación 1 (cuadrículas E10 y G11)}

Con unas dimensiones conservadas de $2,80 \times 2 \mathrm{~m}$, sólo se han documentado de ella hasta el momento restos de dos muros paralelos con dirección noroeste-noreste. Estos paramentos están realizados con piedras de medianas y grandes dimensiones trabadas con tierra y pequeños ripios. El primero de ellos (U.E. 1004), tiene una longitud de $0,70 \mathrm{~m}$ y una anchura de $0,50 \mathrm{~m}$, presentando restos de una hilada y las piedras de trabazón de la segunda con una altura total de $0,25 \mathrm{~m}$; en su parte noroeste se abre un vano de acceso hacia la habitación 2 de 1,26 $\mathrm{m}$ de ancho que posteriormente es transformado en hogar. El segundo muro (U.E. 1023) de $1 \times 0,50 \mathrm{~m}$ conserva sólo una hilada de piedras con una altura máxima de $0,20 \mathrm{~m}$, abriéndose igualmente en su parte noreste otro vano de $0,80 \mathrm{~m}$ de anchura que comunica con la habitación 3 . El pavimento de esta estancia, está formado por una tierra apisonada dura y compacta de color gris con carboncillos, que es cortada a la altura del umbral abierto en la U.E. 1004, cuando éste sufre la transformación arriba mencionada. Este suelo tiene además un roto de $1 \times 1,10 \mathrm{~m}$ al noroeste en la intersección de los perfiles norte y oeste de la cuadrícula F10 (fig.4).

En la excavación de este espacio se han documentado cuatro niveles que agrupan un total de 9 UU.EE. (fig.5)

NIVEL SUPERFIGIAL

Está formado por las UU.EE. 1000 que cubre toda la superficie del yacimiento y 1018.

U.E. 1000.-Tierra superficial de labor de color marrón, suelta con abundantes raíces. Presenta una fuerte inclinación norte-sur. La potencia máxima es de 0,60 $\mathrm{m}$ al norte, y la mínima de 0,24 $\mathrm{m}$ al sur. Cotas desde 


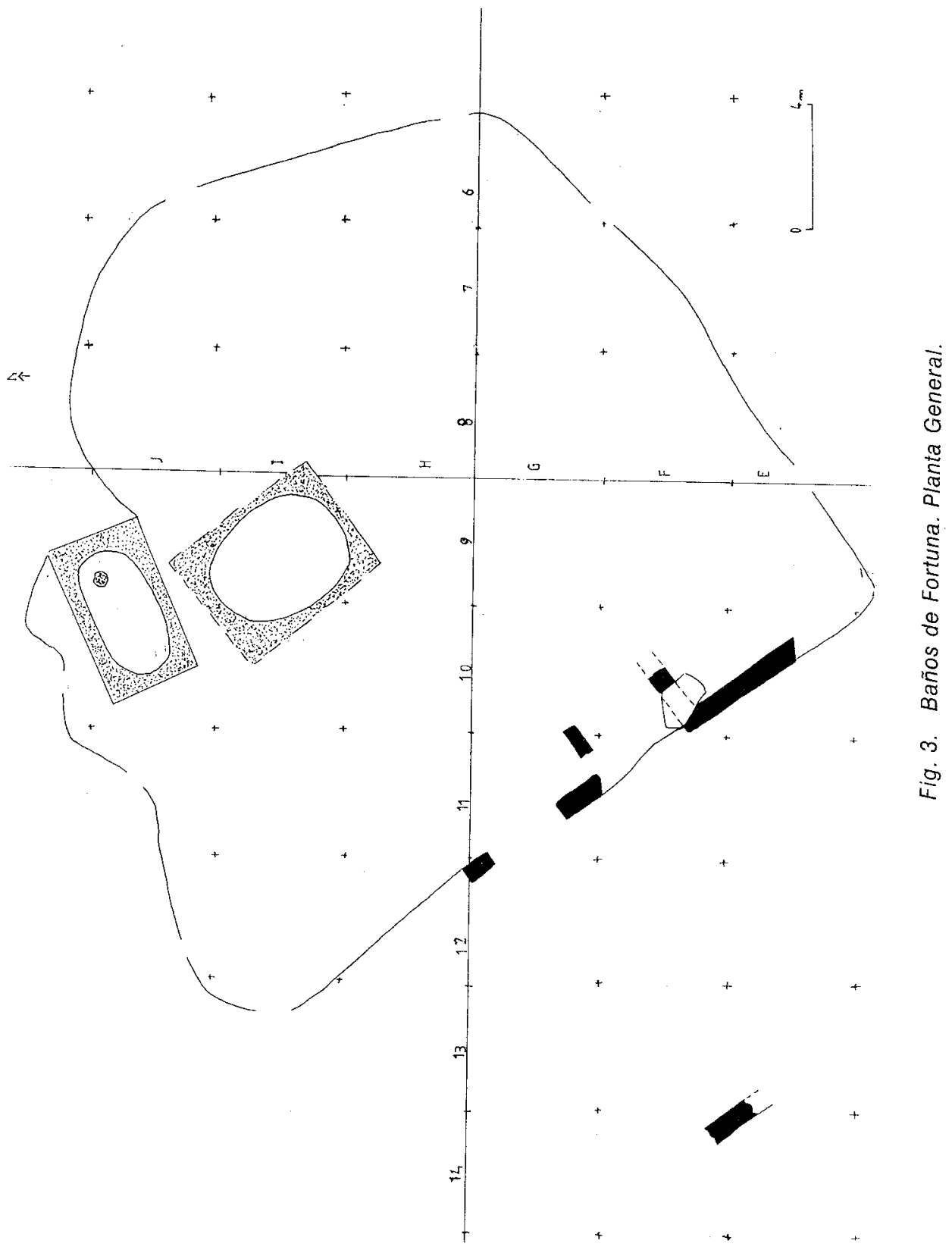


<smiles>[CH]CC</smiles>
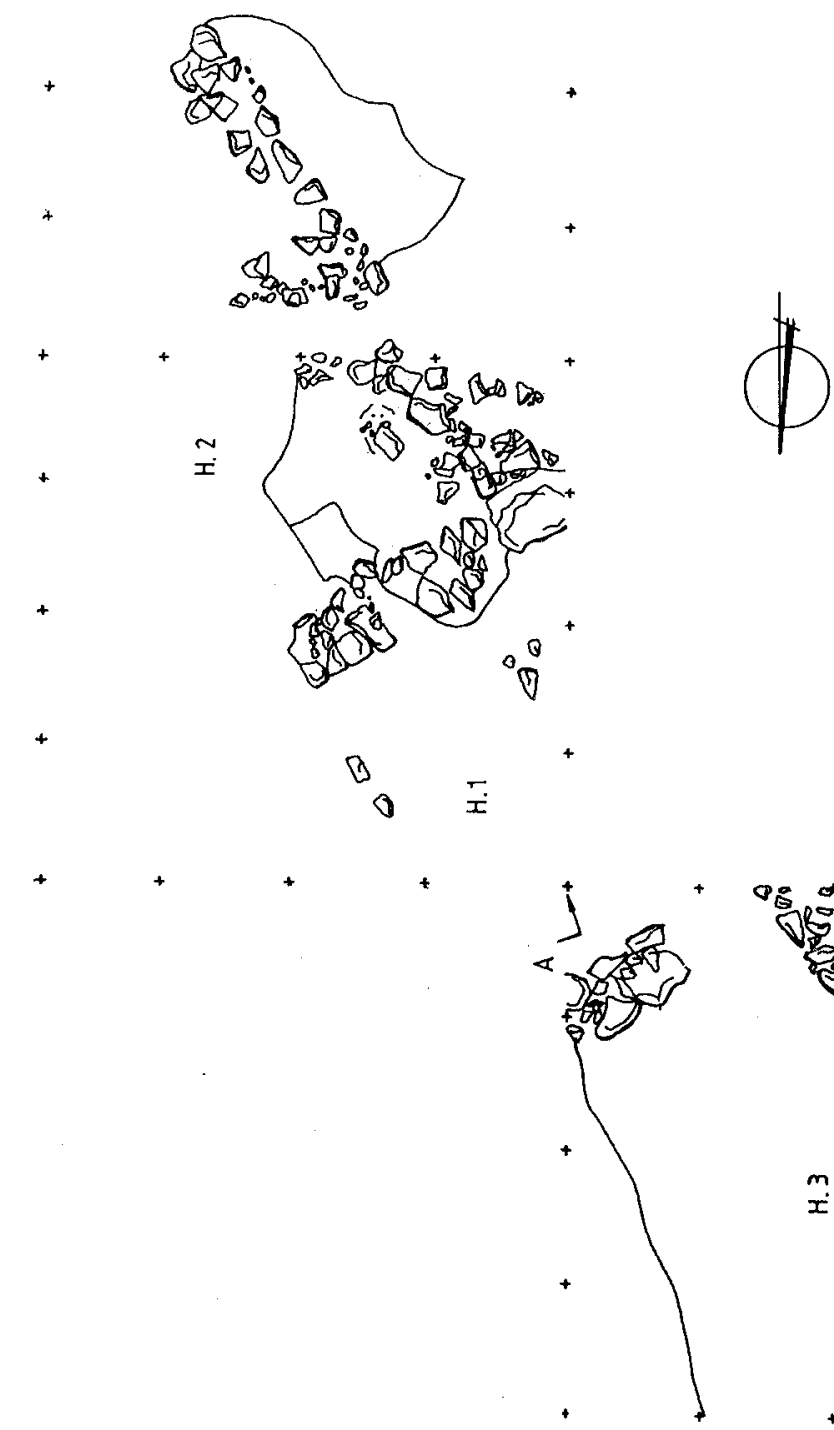


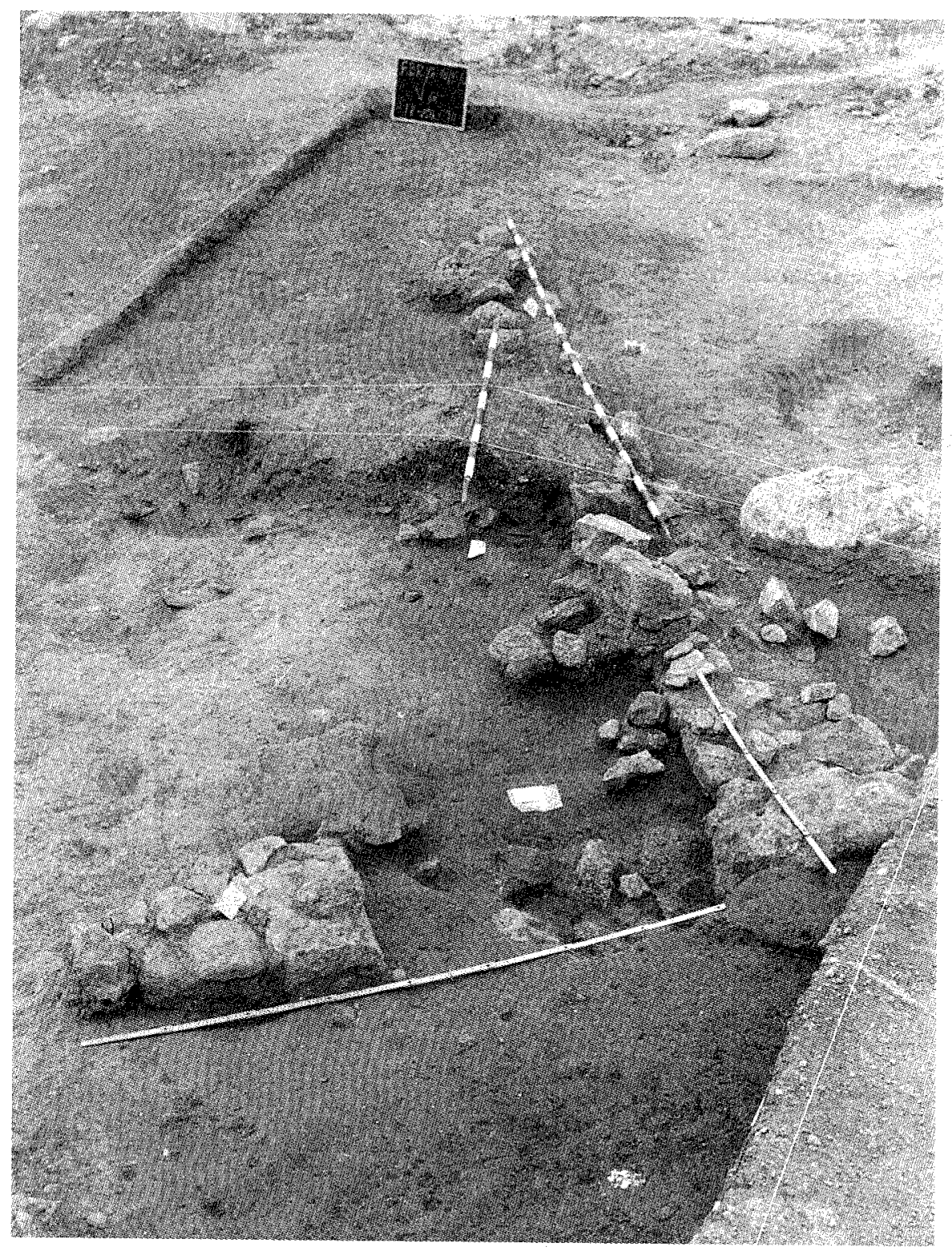

Fig. 5. Baños de Fortuna. Habitaciones 1 y 2. Vista general. 
el punto cero ideal entre $+0,79$ y $+0,80 \mathrm{~m}$. Cubre a las UU.EE. 1001, $1002,1004,1010,1011,1012,1016,1017$, y 1018. Entre el material significativo recuperado en esta U.E. destacan fragmentos de borde y pared de T.S.G. -formas Drag. 18, 27, 24/25, y 45-, marmorata -Forma Drag. 18 - , producciones africanas en A2 - forma Hayes 14A- africanas de cocina - forma Hayes 197-, restos de volutas y margos de lucernas de los siglos I y II -tipos Bailey A y $\mathrm{P}$ grupo L, y cerámica común y gris de cocina romana, todo ello mezclado con platos modernos de loza blanca y cerámica vidriada.

U.E. 1018.-Bolsa de tierra marrón muy blanda que rellena la fractura que sobre el pavimento se realizó como consecuencia de tareas agrícolas antiguas (U.E. 1026). Potencia máxima $0,20 \mathrm{~m}$, mínima $0,06 \mathrm{~m}$. Cota desde el punto cero ideal entre $+0,20 \mathrm{y}+0,06 \mathrm{~m}$. El único material aportado por esta U.E. es un fragmento de cerámica vidriada moderna con vedrio verde claro al interior y verde oscuro al exterior. Esta bolsa corta a la U.E. 1001.

NiVel I

Estrato de relleno compuesto por una tierra amarilla arenosa y blanda (U.E. 1001), que aparece ocupando parte del interior de la habitación 1. Presenta irregularidades en su superficie debidas a las tareas agrícolas. Potencia máxima $0,30 \mathrm{~m}$, mínima 0,08 . Cotas desde el punto cero ideal entre $+0,29 y+0,19 \mathrm{~m}$. Cubre a la U.E. 1017. El material aportado por esta U.E. es muy abundante, destacando producciones gálicas -formas Ritt. 5 y 8, Drag. 15/17, 18 y 24/25-, tardoitálicas -Drag. 4-, fragmentos de mangos, volutas y discos de lucernas imperiales —Tipos Bailey A y $B$-, paredes finas - forma Mayet XXXVII-, y abundantes fragmentos de cerámica común y de cocina romana. Cubre a la U.E. 1012, y está cortado por la U.E. 1018.

NIVEL II

Momento de abandono de las estructuras de la habitación, representado por las UU.EE. 1002, 1016, 1017 y 1025:

U.E. 1002.-Bolsa de tierra marrón rojiza que cubre a la U.E. 1016, de $1,60 \times 1,12 \mathrm{~m}$. Potencia máxima $0,24 \mathrm{~m}$ mínima $0,10 \mathrm{~m}$. Cotas desde el punto cero ideal entre $+0,23$ y $0,09 \mathrm{~m}$. Material significativo: T.S.G. lisa de la forma Drag. 15/17, y decorada -Drag. 29-; lucernas de los tipos Bailey $\mathrm{B}$ y $\mathrm{P}$; restos de ímbrices; cerámica gris romana; cerámica común romana de los tipos Vegas $37,38.10$ y 16.2.; huesos de animales.

U.E. 1016.-Cenizas del interior del hogar. Potencia máxima $0,16 \mathrm{~m}$, minima 0,10 $\mathrm{m}$. Cotas desde el punto cero ideal entre $+0,06 \mathrm{y}+0,02 \mathrm{~m}$. 
Está cubierto por la U.E. 1002, y rellena a la U.E. 1025. Material significativo: T.S.G. de las formas Ritt. 1 y 8 , Drag. 18 y 27 ; paredes finas: tipo Atlante 2/293; lucernas imperiales: tipos Bailey B grupo I (pieza completa y fragmentos de otra) y Bailey $P$ grupo I; cerámica de cocina romana: ollas de borde vuelto; cerámica común romana: restos de jarras, tapaderas.

U.E. 1025.-Hogar. Es de forma pentagonal con unas dimensiones de $1,40 \times 1,70 \mathrm{~m}$. y una altura de $0,14 \mathrm{~m}$. Está relleno por la U.E. 1016 y corta a la U.E. 1012. En el fondo se localiza un lecho de piedras que pudieran pertenecer a la cimentación de la U.E. 1004.

U.E. 1017. - Tierra gris con raices y piedrecillas pequeñas, blanda y húmeda, que está depositada directamente sobre el pavimento de la habitación 1 (U.E. 1012). Potencia máxima $0,08 \mathrm{~m}$, mínima 0,02 m. Cotas desde el punto cero ideal entre $+0,08$ y $+0,02$. Material significativo: T.S.G. formas Drag. 18, 27, 24/25, 29 y Ritt. 8; marmorata de las formas Ritt. 8 y Drag. 18; fragmentos de lucernas imperiales del tipo Bailey B; ollas de borde vuelto en cerámica gris de cocina romana; huesos de animales. Está cubierto por la U.E. 1001.

Nivel III

Corresponde al momento en que la puerta abierta en la U.E. 1004 es transformada en hogar, remodelando la distribución de la habitación 1.

NIVEL IV

Está constituida por las UU.EE. que forman la habitación en sí, UU.EE. 1004, 1010 y 1012.

\section{VII.2. Habitación 2 (cuadrícula E1D)}

Situada al sureste de la anterior y comunicada con ella por la puerta antes mencionada, tiene unas dimensiones apreciables de 4,20 por 1,90 metros. Está formada por un gran muro con dirección noroeste-sureste construido con piedras de medianas y grandes dimensiones trabadas con tierra y pequeños ripios (U.E. 1010). Sus dimensiones son de 4,20 $\times 0,50$ $\mathrm{m}$ y conserva una hilada de $0,25 \mathrm{~m}$ de altura. Su parte superior está muy deteriorada por efecto de las tareas agrícolas. El cierre noroeste de la habitación 2 lo constituye la U.E. 1004 de la que hemos hablado al describir la 1. Toda la habitación está desfondada (cubierta por la U.E. 1000), a excepción del ángulo noroeste donde se conservan restos del pavimen- 
to (U.E. 1012) que es del mismo tipo que el de la habitación 1. Este solamente es apreciable en el umbral de la puerta, donde está roto por el hogar, quedando tan sólo un fragmento a lo largo de la U.E. 1010 de $1 \times$ $0,50 \mathrm{~m}$ (fig. 4). Aqui aparecieron colocadas sobre el pavimento, in situ, dos ollas de borde vuelto en cerámica romana gris, y una botella globular completa con cuello muy corto y labio engrosado de sección triangular de cerámica de tradición ibérica, engobada en naranja y decorada con bandas de color rojo granate.

En la zona donde conserva estratigrafia (ángulo noroeste), tiene las mismas UU.EE. que la habitación 1, con idéntico material, adscribibles por tanto a los niveles arriba descritos. Al nivel superficial (UU.EE. 1000 y 1018) se añade aquí la U.E. 1011 que forma una bolsada cubierta por la U.E. 1000 , de $2,20 \times 0,80 \mathrm{~m}$. Se localiza al exterior de la habitación 2 y paralela a la U.E. 1010; en el interior se reduce a una pequeña mancha de $0,70 \times 0,10 \mathrm{~m}$. Cota desde el punto cero ideal $-0,18 \mathrm{~m}$. No aportó ningún tipo de material (fig. 5).

\section{VII.3. Habitación 3 (Cuadrícula G11)}

Al noroeste de la habitación 1 y con unas dimensiones provisionales de $4,50 \times 3,50 \mathrm{~m}$. Se compone de un gran muro noroeste-sureste, continuación de la U.E. 1010, construido con la misma técnica que los hasta ahora descritos (U.E. 1022). Su longitud es de $4,80 \mathrm{~m}$, aunque tiene una gran rotura en su parte central de $2 \mathrm{~m}$. La anchura es de 0,50 $\mathrm{m}$, conserva una hilada de piedras con una altura de $0,20 \mathrm{~m}$. El cierre sureste está formado por la U.E. 1023, que es medianera entre las habitaciones 1 y 3. Las estructuras de esta habitación en su zona oeste están muy destruidas y alteradas como consecuencia de lo superficial que se encuentran aquí los restos (fig. 4). La excavación de la habitación 3 aún no ha concluido, por lo que tenemos representados hasta el momento el nivel superficial con las UU.EE. 1000 y $100 \mathrm{~A}$, nivel $\mathrm{I}$ al que tenemos que añadir aquí las UU.EE. 1020 y 1021, y el nivel IV con las UU.EE. 1022 y 1023 (fig. 6).

NIVEL SUPERFICIAL

U.E. 1000.-Superficial general, compuesto por una tierra marrón suelta con abundantes raíces. Tiene una fuerte inclinación en dirección esteoeste. Potencia máxima $0,62 \mathrm{~m}$, mínima $0,04 \mathrm{~m}$. Cotas desde el punto cero ideal entre $+0,93$ y $-0,20 \mathrm{~m}$. El material significativo de este estrato se compone de fragmentos de platos de loza blanca, T.S.G. de la forma Drag. 27 y cerámica común, y gris romana. Cubre a las unidades estratigráficas 1000A, 1001, 1018, 1020, 1022 y 1023. 

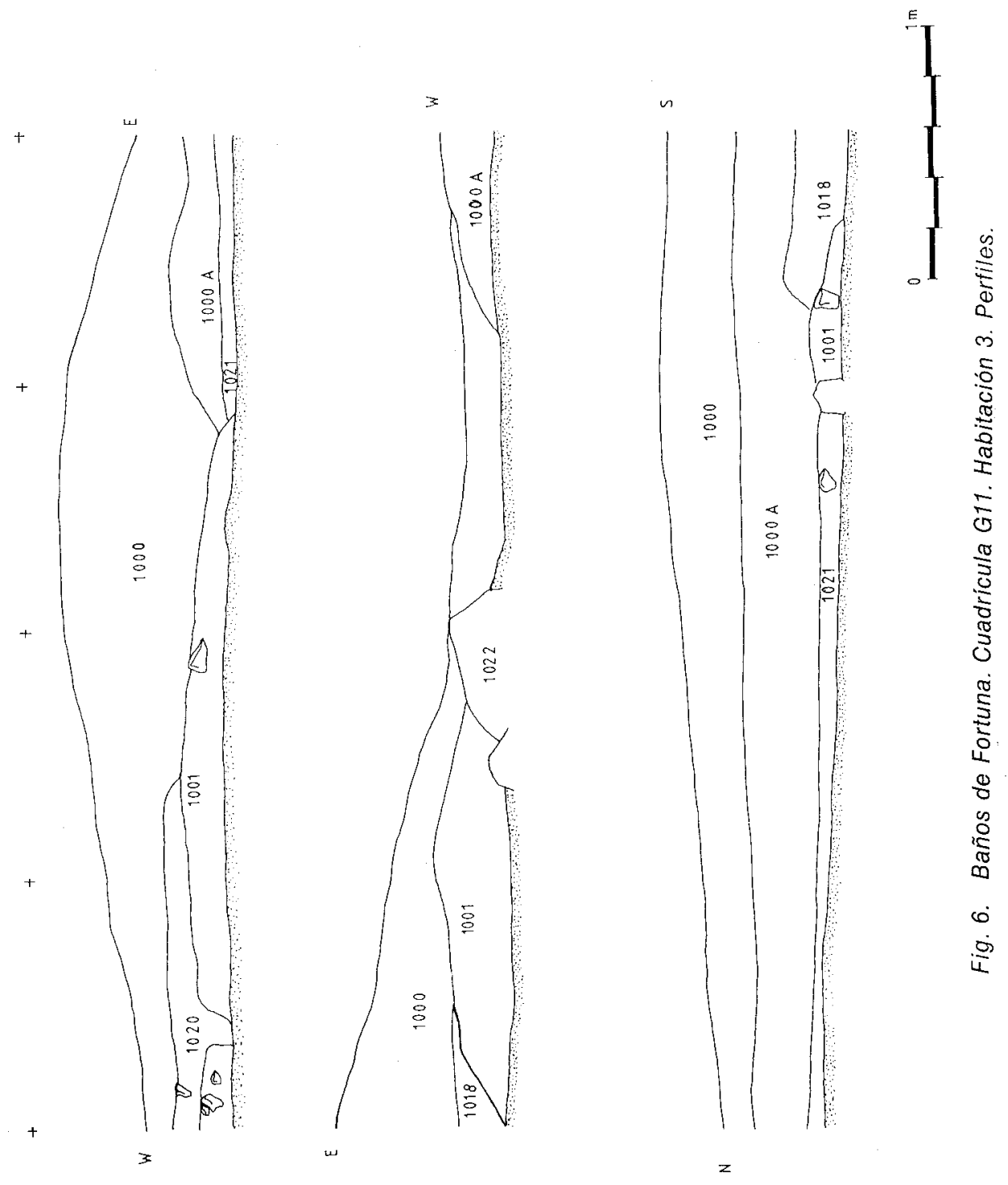
U.E. 1000A.-Tierra marrón similar a la anterior, pero algo más compacta, que se extiende en una superficie de $1,20 \times 4 \mathrm{~m}$ en la zona este de la cuadrícula. Potencia máxima $0,30 \mathrm{~m}$, mínima $0,04 \mathrm{~m}$. Cotas desde el punto cero ideal entre $+0,30 \mathrm{y}+0,51 \mathrm{~m}$. Cubre a las UU.EE. 1001, 1018 y 1021. El material significativo se compone de T.S.G formas Drag. 27 y 18; producciones africanas en A2 tipo Hayes 23A; cerámica gris romana; restos de ollas en cerámica vidriada de color marrón; fragmentos de huesos de animales.

\section{NIVEL I}

U.E. 1001.-Estrato de tierra amarilla que aparece ocupando una superficie de $2,16 \mathrm{~m} \times 4,20 \mathrm{~m}$, al este y oeste de la habitación 3 no aparece, siendo sustituido por la U.E. 1021 y 1000 respectivamente. Potencia máxima $0,30 \mathrm{~m}$, minima $0,10 \mathrm{~m}$. El material significativo de esta U.E. en la habitación 3 presenta unas diferencias con respecto al mismo estrato en la habitación 2. Mientras que en esta última las producciones T.S.G, marmorata y lucernas de los tipos Bailey A y B, están profusamente representadas, en la habitación 3 , este material es muy escaso (dos fragmentos T.S.G formas Drag. 18 y 27, y restos de una voluta y pico de lucerna del tipo Bailey A), siendo sin embargo muy abundantes los fragmentos de enlucido de pared de color blanco, restos de pavimento de opus signinum, trozos de metal (clavos), fragmentos de ollas de cocina romanas, fragmentos de huesos de animal, y conchas de moluscos marinos. También se recuperaron tres monedas de módulo grande, actualmente en proceso de limpieza. Cubre a la U.E. 1024, está cortado por las UU.EE. 1018 al sur y 1020 al oeste.

U.E. 1020.-Bolsada de ceniza localizada al noroeste de la habitación. Tiene unas dimensiones de $0,62 \times 1,30 \mathrm{~m}$, su potencia máxima es 0,20 centímetros (donde corta a la U.E. 1001), y la minima de 0,06 m. Cota desde el punto cero ideal $+0,59 \mathrm{~m}$. El material de esta U.E. se compone de algunos fragmentos de ollas de cocina romanas. Esta cubierto por la U.E. 1000, y corta a la U.E. 1001.

U.E. 1021.--Tierra marrón con chinarro muy suelta que aparece directamente bajo el $1000 \mathrm{~A}$, formando una mancha triangular de 3,20 $\mathrm{m}$ de longitud por $1,12 \mathrm{~m}$. de base junto al perfil este de la cuadrícula. Potencia máxima $0,16 \mathrm{~m}$ al este, mínima $0,06 \mathrm{~m}$ al norte. Cota desde el punto cero ideal entre $+0,09$ y $0 \mathrm{~m}$. Entre el material recuperado, destaca un fragmento de T.S.G. de la forma Drag. 33, cerámica común y de cocina romana.

La estratigrafía de esta habitación se completa con la U.E. 1024 que es una tierra rojiza con chinarro, raices y manchas de ceniza que no se 
rebajó y por el momento no incluimos en ninguno de los niveles descritos. Cotas desde el punto cero ideal entre $+0,20 \mathrm{y}+0,10 \mathrm{~m}$.

\section{VII.4. Excavación en las cuadrículas E14 y F14}

Situadas 12 metros al oeste de las anteriores, solamente se rebajó la U.E. 1000 de ambas, bajo la cual aparecieron restos de un muro de iguales características de los anteriores de $1,5 \times 0,5 \mathrm{~m}$, paralelo a los 1010 y 1022. Es posible que esta estructura, junto a las antes descritas, forme parte de algún tipo de edificación, extremo que deberá esperar a futuras campañas arqueológicas para ser, en su caso, confirmado (fig.3).

\section{VII.5. Excavación en el depósito 1 (U.E. 2000)}

De forma cuadrangular al exterior y circular al interior, con dirección noroeste-sureste, ocupa las cuadrículas $\mathrm{H} 9,19, \mathrm{J9}$, e I10. Está realizado a base de opus caementicium recubierto por opus signinum rojo de buena calidad. Tiene unas dimensiones totales de $5 \times 4,30 \mathrm{~m}$ al exterior y $4 \times$ 3,40 al interior. La profundidad hasta el pavimento (U.E. 2007) es de 2 m; éste está destruido casi en su totalidad, a excepción de un fragmento conservado al suroeste de $2,50 \times 50 \mathrm{~m}$ donde se aprecian restos de una cubeta circular de limpieza con $0,10 \mathrm{~m}$ de profundidad y $0,50 \mathrm{~m}$ de diámetro. El rudus del suelo con $0,20 \mathrm{~m}$ de grosor se asienta sobre un lecho de piedras pequeñas (U.E. 2006) que se encuentran incrustadas en el terreno natural, donde se excava la fosa del depósito. La unión de las paredes con el pavimento se realiza a través de cuartos de círculo (fig.7). La excavación del interior de esta estructura aportó un total de siete UU.EE. (fig.8), cinco de las cuales corresponden a un nivel de relleno moderno formado una vez destruido el pavimento, y las dos restantes al nivel de construcción de la balsa (UU.EE. 2006 y 2007).

VII.5.1. Nivel de relleno moderno. Interior depósito 1 (U.E. 2000)

U.E. 2001.-Estrato de tierra amarilla con inclinación norte-sur. Potencia máxima $0,30 \mathrm{~m}$, minima $0,06 \mathrm{~m}$. Cotas desde el punto cero ideal entre $-1,33$ y $-1,77 \mathrm{~m}$. Material significativo: fuentes y platos de loza blanca moderna, junto a algunos fragmentos de cerámica común y ánforas (Dressel 2/4) romanas. Cubre a la U.E. 2002.

U.E. 2002.-Tierra marrón grisácea con abundantes raíces, que se extiende de manera uniforme. Potencia máxima $0,28 \mathrm{~m}$, mínima $0,10 \mathrm{~m}$. Co- 


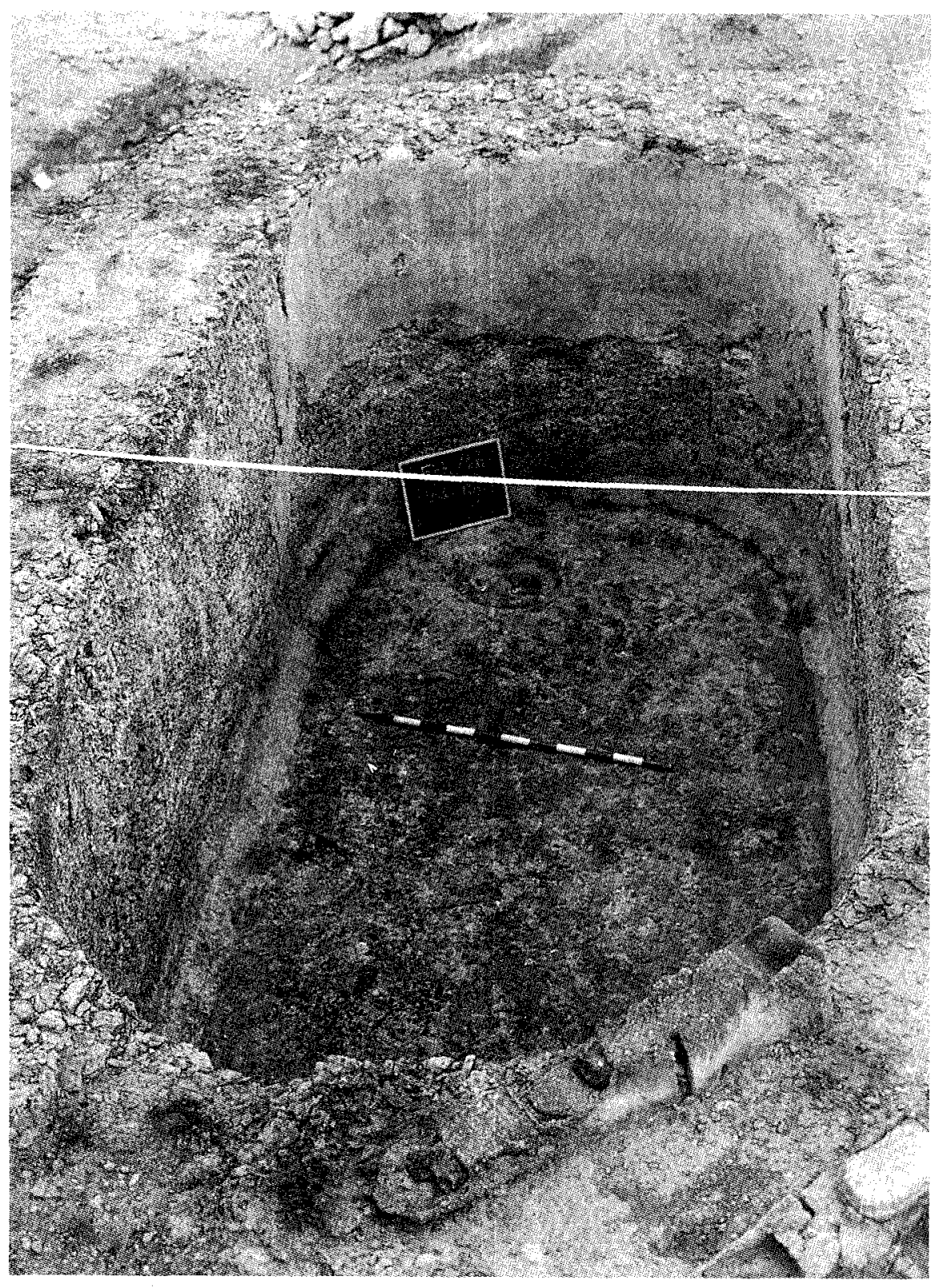

Fig. 7. Baños de Fortuna. Depósito pequeño. Vista general. 


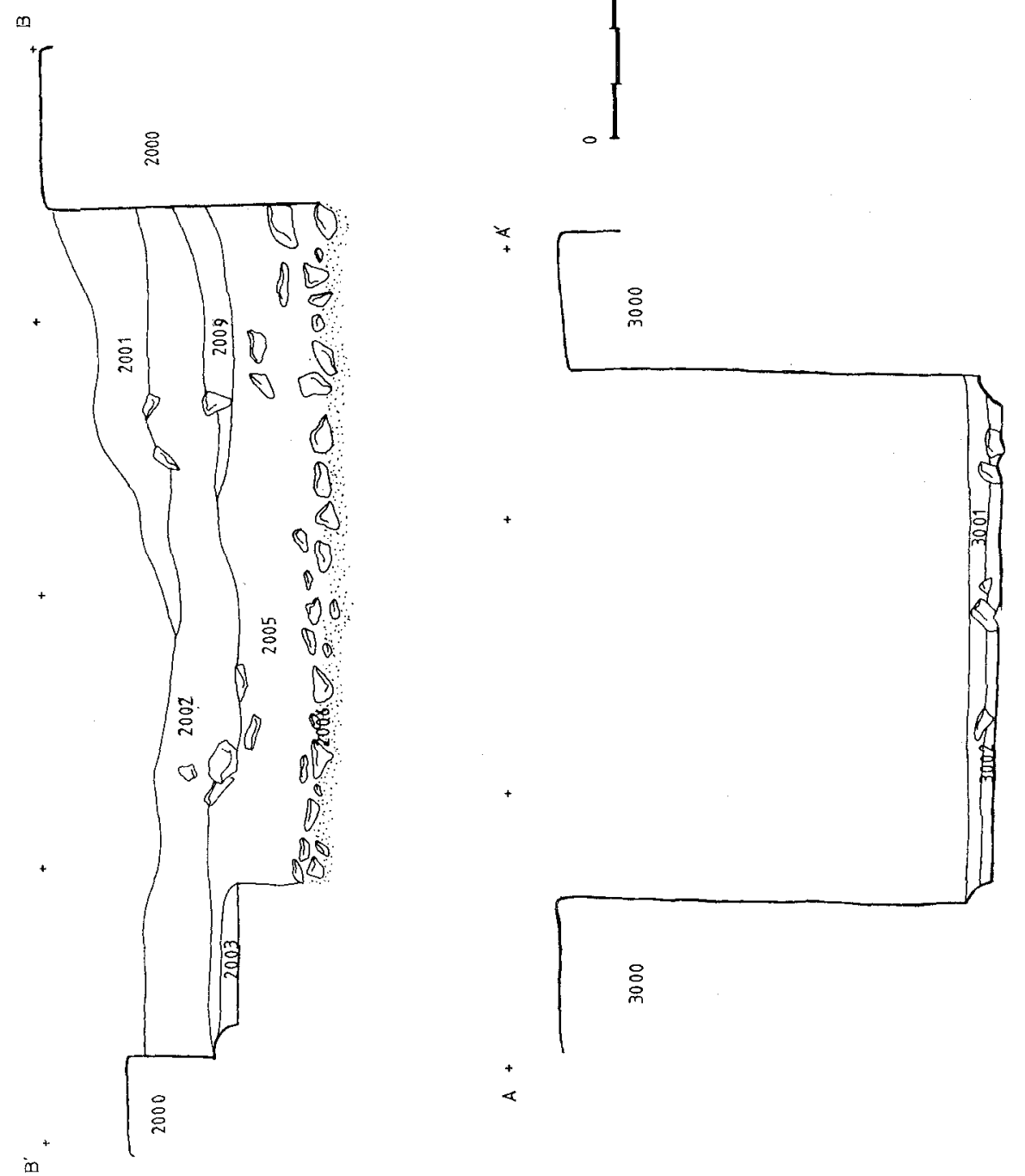


tas desde el punto cero ideal entre $-1,63$ y $-1,70 \mathrm{~m}$. Junto a dos fragmentos de ánforas de los tipos Dressel $2 / 4$ y $7 / 11$, aparece gran cantidad de loza blanca moderna, cerámica vidriada, y restos de opus signinum. Cubre a las UU.EE. 2004 y 2005.

U.E. 2003.-Bolsada de limos de color marrón, que sólo aparece en aquellas zonas que conservan restos de pavimento (ángulo suroeste). Potencia máxima $0,08 \mathrm{~m}$, mínima $0,02 \mathrm{~m}$. Cotas desde el punto cero ideal entre $-1,94$ y $-2,02 \mathrm{~m}$. No aportó material significativo. Cubre a la U.E. 2007 (pavimento), y está cubierta por la U.E. 2005.

U.E. 2004.-Bolsada de tierra amarillenta, arenosa y húmeda, que presenta fuerte inclinación con dirección norte-sur. Potencia máxima 0,20 metros, minima $0,02 \mathrm{~m}$. Cotas desde el punto cero ideal entre $-1,73 \mathrm{y}-$ 1,93 metros. Solamente se exhumó en esta U.E. un fragmento de plato de loza blanca. Cubre parcialmente a la U.E. 2005.

U.E. 2005.-Estrato de tierra gris clara con piedras. Se extiende por todo el depósito con una potencia que oscila entre los $0,02 \mathrm{~m}$ y $0,32 \mathrm{~m}$. Cotas desde el punto cero ideal entre - 1,93 y - 1,94 m. El material significativo es de las mismas caracteristicas que el hasta ahora mencionado para el resto de las UU.EE. de este nivel. Cubre a las UU.EE. 2003 y 2006.

\section{VII.5.2. Nivel de construcción del depósito}

Lo forman las UU.EE. 2007 (pavimento), y 2006. De ambas hemos hablado al hacer la descripción de la U.E. 2000. Sólo añadir que durante la excavación de la U.E. 2006, no se recuperó ningún tipo de material arqueológico. Ante esta circunstancia, y con objeto de poder fechar el momento de construcción de este depósito, se decidió afrontar la excavación de la cuadrícula $\mathrm{H} 9$ situada junto al ángulo sur del mismo. El resultado de este trabajo no respondió a nuestras esperanzas, puesto que exceptuando los estratos del nivel superficial (UU.EE. 1000 y 1000A), el resto de UU.EE. $(1003,1005$, y 1006) no proporcionaron ningún tipo de material arqueológico.

\section{VII.6. Excavación del depósito 2 (U.E. 3000)}

De forma rectangular al exterior y ovalado al interior, con dirección noroeste-sureste, ocupa las cuadrículas $\mathrm{J} 9, \mathrm{~J} 10, \mathrm{~K} 9$, y $\mathrm{K} 10$. La técnica constructiva empleada en él es la misma que la del depósito 1 . Tiene unas dimensiones totales de $6,26 \times 3,10 \mathrm{~m}$ al exterior y $5 \times 1,74 \mathrm{~m}$ al 
interior; la profundidad hasta el pavimento es de 1,60 m. Se conserva en perfecto estado, con el pavimento (U.E. 3003) y la paredes intactas, gracias a que ha sido utilizado hasta fecha relativamente reciente como balsa de riego. A este último momento de uso corresponden una serie de canalizaciones modernas que se le adosan en superficie, así como las reformas sufridas por el enlucido de las paredes y el desagüe añadido en su esquina noreste donde se aprecian restos de cemento. El pavimento se une a las paredes por medio de cuartos de círculo, y conserva al noreste una cubeta de limpieza de $0,10 \mathrm{~m}$ de profundidad y $0,40 \mathrm{~m}$ de diámetro (fig. 9). La excavación del interior del depósito 2, proporcionó dos UU.EE. (3001 y 3002), sedimentadas una vez dejado fuera de uso como balsa de riego en época reciente (fig. 8).

U.E. 3001. - Estrato de tierra marrón blanda con abundantes raíces. Potencia $0,04 \mathrm{~m}$. Cota desde el punto cero ideal $-1,50 \mathrm{~m}$. Entre el escaso material proporcionado por este estrato destacan un fragmento de asa del tipo Gala 4, junto a platos de loza blanca y cerámica vidriada y común moderna. Cubre a la U.E. 3002.

U.E. 3002.-Limos amarillos que descansan directamente sobre el pavimento de la balsa. Potencia $0,06 \mathrm{~m}$. Cota desde el punto cero ideal -

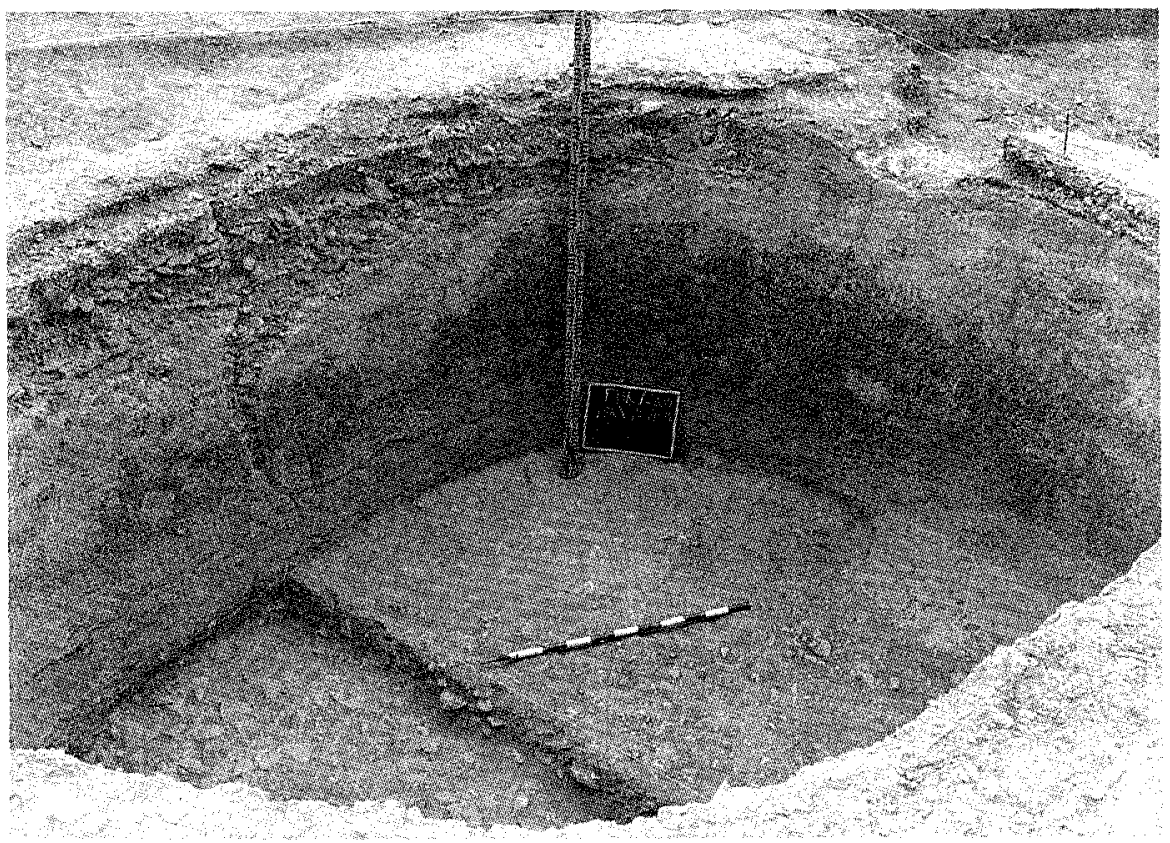

Fig. 9. Baños de Fortuna. Depósito grande. Vista general. 
1,54. El material de esta U.E. se compone de fragmentos de contenedores de agua modernos.

\section{CRONOLOGIA E INTERPRETACIÓN}

El estado actual de las investigaciones en el yacimiento de «Los Baños Moros», y lo exiguo de los restos hasta ahora encontrados, no nos permiten presentar conclusiones definitivas sobre la naturaleza de los mismos. No obstante, y como hipótesis de trabajo, parece claro que las estructuras por el momento exhumadas están en relación directa con el aprovechamiento del manantial de aguas minero-medicinales existente en la zona, pudiendo formar parte, de un primer establecimiento termal romano previo a la construcción del edificio cuyas ruinas identificadas como «moras» nos describe el Dr. Lacort. La confirmación en su caso de este extremo, queda a expensas de futuras campañas de excavación, tanto en la zona objeto de estudio en la actualidad, como en la superficie ocupada por los restos de los llamados Baños Viejos, bajo cuyos cimientos, presumiblemente deben encontrase las ruinas balnearias romanas con todo el complejo que como en el caso de Cabeza de Buey acompaña a este tipo de asentamientos ${ }^{27}$.

En cuanto a la cronología de los restos, en función a la estratigrafía proporcionada por los niveles de las cuadrículas excavadas hasta el momento, hemos establecido IV fases provisionales en la ocupación del yacimiento, siempre sujetas a las modificaciones que posteriores campañas puedan introducir.

Fase 1.-Corresponde al período de reutilización de los depósitos 1, y 2. Por el material que las UU.EE. 2001, 2002, 2003, 2004, 2005, 3001 y 3002 , han proporcionado, esta fase podría extenderse desde finales del siglo $\mathrm{XIX}$ hasta la primera mitad del $\mathrm{xx}$.

Fase 11.-Abandono de las estructuras romanas. En base al material recuperado en el nivel II de las habitaciones 1 y 2, podemos establecer

${ }^{27}$ Calero Carretero, J. A., "El complejo termal romano de "La Nava" (Cabeza de Buey, Badajoz). Cuatro campañas de excavaciones (1979-1983)", Extremadura Arqueológica I. Salamanca 1988, págs. 155-166. 
un marco temporal para esta fase situado entre finales del reinado de la dinastía Julio-Claudia y principios de los Flavios ${ }^{28}$.

Fase III.-Corresponde al momento en que la puerta abierta en la U.E. 1004 es transformada en hogar, remodelando la distribución de la habitación 1. Los materiales que marcan el final del uso de esta habitación (fase II), establecen un término ante quem para la misma situado hacia la primera mitad del siglo $1 \mathrm{~d}$. C.

${ }^{28}$ El perfil de la Ritt. 1 es típicamente itálico, siendo adoptado por los primeros talleres gálicos. El inicio de la producción se puede situar en torno a los años $5 / 15 \mathrm{~d}$. C. (BELTRÁN Lloris, A., Guía de la Cerámica Romana. Zaragoza 1990, pág. 90), llegando hasta finales de los Julio-Claudios. (Oswald, F.- Price, T. D., Introduction A l'Etude de la Ceramique Sigilée. Revue Archéologique SITES segundo trimestre. Avignon 1984, pág. 119. La forma Ritt. 8 es también de cronología antigua dentro de las producciones lisas. Apareciendo en contextos claudianos (Oswald, F.-Price, T. D., Op. cit., pág 126) y neronianos (FICHes, J. L.; GuY, M.; PONCIN, L., "Un lote de vases sigillées des premieres années du regne de Neron dans l'un des ports de Narbonne", Archeonautica, 2. Narbona 1978, págs. 189-190).

Los platos Drag. 18 y 15/17 tienen una muy amplia difusión. Los primeros presentan un floruit bajo el reinado de Claudio, en época de Domiciano-Trajano adoptan la forma intermedia de la 18/31 (Oswald, F.-Price, T. D., Op. cit., págs. 120-121). Los segundos, en su forma más clásica, que es la representada en nuestro yacimiento corresponden al período comprendido entre los últimos Julio-Claudios [Claudio-Nerón] y los primeros Flavios y sufren un cambio de perfil, como la forma 18, en época de Domiciano-Trajano (OswaLD, F.-PRICE, T. D., Op. cit., págs. 114-117).

La copa Drag. 24/25 inspirada en el perfil itálico Goudineau 38, desaparece según Hofmann al comienzo de la dinastía Flavia (Hofmann, B., La cerámique sigilée. París 1986, pág 59), aunque en Conimbriga aparece en contextos de Claudio-Trajano (Delgado, A.; MAYET, F.; Mouthino, A. Fouilles de Conimbriga. IV. Les sigillées. París 1975, pág. 92). Los ejemplares reproducidos por Oswald y Price están adscritos a claros contextos claudianos (OswaLD, F.-Price, T. D., Op. cit., pág. 112).

El tipo Goudineau 32, es el antecedente más antiguo en engobe rojo de la copa Drag. 27 cuya cronología es muy amplia llegando hasta la mitad del siglo II d. C. (HofmanN, B., La ceramique sigilée. Paris 1986, pág. 59).

La forma Drag. 29 de la que tenemos un fragmento de pared y carena, está atestiguada en Conimbriga entre los años 50 y 75 (Delgado, A.; Mayuet, F.; Mouthino, A., Op. cit., pág. 73). Para Hofmann desaparecen a principios del reinado de los emperadores flavios (HoFMANN, B., Op .cit., pág. 63). En Lérida la mayoría de los vasos estudiados de esta forma no van mas allá del reinado de Nerón a excepción de un solo fragmento (PÉrez Almoguera, $A$. La terra sigillata de l'antic Portal de Magdalena. Lleida 1990, págs. 52-53). Oswald y Price recogen Drag. 29 en contextos tiberio-claudianos y flavios (OswALD, F.- Price, T. D., Op. cit., págs. 40-47).

La taza de paredes finas Atlante $2 / 293$ ha sido recuperada en Ostia en contextos flavios y Adrianeos (RIcCl, A., "Ceramica a paretti sottilli», en Atlante delle forme ceramiche $/ 1$. Ceramica fine romana nel Bacino Mediterraneo (Tardo e Ellenismo e primo Impero). Roma 1985, págs. 301-302.

La lámparas del tipo Bailey $B$ grupo I según el autor comprende el periodo de los reinados de Augusto a Tiberio (A Catalogue of the Lamps in the British Museum 2, págs. 153155). Para el tipo $P$ grupo I Bailey propone como marco temporal el reinado de los últimos Flavios y primeros antoninos (BAlley, D. M., Op. cit., págs. 314-317). 
Fase IV.-Está constituida por las UU.EE. que forman la habitaciones 1, 2, y 3 (UU.EE. 1004, 1010, 1012, 1022 y 1023), y los depósitos 1 y 2 (U.E. 2000 y 3000). El momento de construcción de estás estructuras, está aún por determinar, puesto que no hemos excavado todavía su estratos de fundación. No obstante, y en función de que la fase anterior nos marca un límite temporal hacia arriba de la primera mitad del siglo । d. C., y teniendo en cuenta que el material más antiguo proporcionado por el nivel superficial general del yacimiento está formado por T.S.I de las formas Goudineau 38,31 y $17 \mathrm{~B}$ fechadas en época augustea ${ }^{29}$, nos aventuramos a situar el inicio de esta fase en un momento impreciso del reinado de Augusto.

TABLA I. FASES DE OCUPACIÓN DE LA ZONA EXCAVADA

\begin{tabular}{|c|l|l|}
\hline FASES & \multicolumn{1}{|c|}{ ESTRUCTURAS } & \multicolumn{1}{c|}{ CRONOLOGÍA } \\
\hline$I$ & $\begin{array}{l}\text { Reutilización moderna de los } \\
\text { depósitos 1 y 2 }\end{array}$ & Siglos XIX y XX \\
\hline II & $\begin{array}{l}\text { Abandono de las estructuras } \\
\text { romanas excavadas }\end{array}$ & $\begin{array}{l}\text { Finales Julio-Claudios principio } \\
\text { de los Flavios }\end{array}$ \\
\hline III & $\begin{array}{l}\text { Remodelación de las } \\
\text { habitaciones 1 y 2 }\end{array}$ & $\begin{array}{l}\text { Término ante quem primera } \\
\text { mitad del siglo 1 d. C. }\end{array}$ \\
\hline IV & $\begin{array}{l}\text { Momento de construcción de } \\
\text { las estructuras romanas } \\
\text { excavadas }\end{array}$ & $\begin{array}{l}\text { Momento impreciso del } \\
\text { reinado de Augusto }\end{array}$ \\
\hline
\end{tabular}

${ }^{29}$ Ver al respecto Goudineau, Ch., La ceramique aretine lisse. Paris 1968, págs. 291, 301, y 305-306. 


\section{DIAGRAMA ESTRATIGRÁFICO}

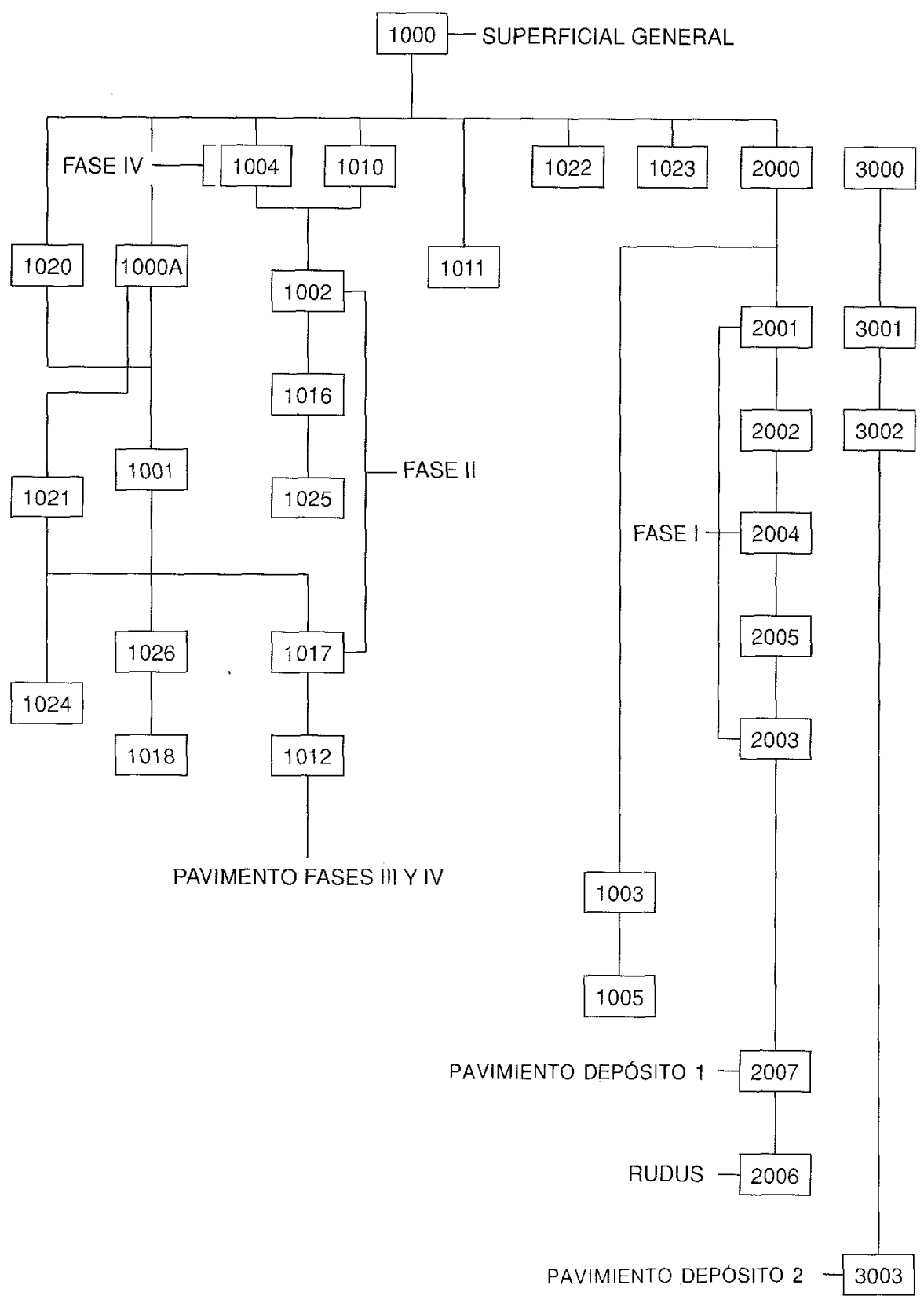




\section{LA ULTERIOR HISTORIA DEL BALNEARIO}

Puestos en relación con la Dirección del Balneario, con cuyo permiso y apoyo hemos trabajado hasta ahora, hemos podido saber igualmente algunos datos más sobre la historia del centro. Hemos sabido de noticias sobre hallazgos de comienzo de siglo, sobre el traslado de lugar del establecimiento termal desde los Baños Viejos a su actual emplazamiento y estamos intentando investigar la localización exacta de los baños de época romana, sin que por el momento hayamos llegado a conclusiones definitivas, en cuya elaboración, sin embargo continuamos trabajando afanosamente.

\section{LOS NUEVOS HORIZONTES DEL ESTUDIO DE LOS EPIGRAFES DE LA CUEVA NEGRA}

El hallazgo del yacimiento en el balneario, la cercanía de las aguas termales a la Cueva Negra (unos dos kilómetros en línea recta) con ambos puntos como elementos referenciales en la toponimia ${ }^{30}$, la importancia de la fuente termal en la vida local en todo tiempo, pero de manera especial en época romana y las características hasta ahora detectadas del yacimiento ${ }^{31}$ nos llevan a inclinarnos por la integración del balneario como contexto arqueológico para la Cueva Negra y sus inscripciones.

El resultado arqueológico hasta ahora conseguido nos sitúa ante un sector del yacimiento que surge en época augustea y que se cierra a fines del siglo I, justamente cuando comienzan las inscripciones en la Cueva Negra. Por otra parte sospechamos que el lugar de los «Baños Viejos», que apenas si distan cincuenta metros del punto sobre el que estamos

\footnotetext{
${ }^{30}$ La senda que une casi en línea recta el balneario con la Cueva Negra se llama en unos mapas "Senda de la Cueva Negra» y en otros "Senda de los Baños» o quizá sea más exacto que se llame en la mitad este "Senda de los Baños" y en la mitad oeste «Senda de la Cueva Negra».

${ }^{31}$ El avance de las excavaciones o de las prospecciones afortunadas podrán ir aclarando los restos romanos de la zona. Hasta ahora el material recuperado es únicamente del siglo Id. C., lo que nos lleva a poder formular hipótesis de trabajo sumamente interesantes como luego diremos. El problema es que aún no está demostrado que sólo haya material de plena época romana sino que es de suponer que las cosas se enriquezcan y se compliquen con el avance de la investigación.
} 
trabajando, debe haber sido el lugar en el que estuvieron situados los baños romanos y que seguramente constituyeron un complejo constructivo que sustituyó al edificio que hasta ahora hemos descubierto y al lugar en el que se realizaban las operaciones médicas en época anterior. Finalmente la no identificación hasta ahora de materiales arqueológicos tardorromanos es otro punto de referencia también a considerar, aunque con la debida prudencia, ya que en este ámbito también puede cambiar la panorámica en cualquier momento.

Apoyándonos en nuestro actual conocimiento de los datos es tentador formular una reconstrucción de la historia que podriamos resumir más o menos asi: en un primer momento el agua surgía en la zona de la gran fractura aún visible en la estructura geológica del terreno y los baños se harían en el lugar mismo de la afloración del agua; al acudir un número importante de bañistas surgió una mansión para servir de hospedería y punto de referencia. Con el auge y el avance de la romanización se construyen los baños a los que se conduce el agua para ser utilizada según los moldes clásicos en la cultura altoimperial y se construyen los edificios que complementan el establecimiento del balneario termal a nivel cultual y hospedero, abandonándose a fines del siglo I d. C. la vieja hospedería que queda inutilizada. Con esta obra constructiva coincide el auge literario de la Cueva Negra. Con la cristianización masiva ya desde los comienzos del siglo IV posiblemente los baños sigan utilizándose, pero el culto pagano queda arruinado y desaparece el uso de escribir en la Cueva Negra y el culto a las Ninfas alli existente. Ello va unido con la aparición de un asentamiento monacal en la zona adyacente a la Cueva por su vertiente norte que daría origen al poblamiento de Caprés sin que podamos de momento precisar la fecha en que tal ocurre.

Pero de todas maneras y haya de verdad en estas hipótesis lo que al final resulte, lo que parece más seguro es que los textos de la Cueva Negra han de ser leídos en el contexto balnear y ello ofrece un interés digno de relieve.

\section{X.1. ¿Fortuna Balnearis?}

En nuestro comentario a los textos de la Cueva ${ }^{32}$ abogábamos por la interpretación del nombre de la villa de Fortuna y nos apoyábamos en la

32 González Blanco, A., "Las inscripciones de Fortuna en la historia de la religión romana. Perspectivas histórico-religiosas», La Cueva Negra de Fortuna (Murcia) y sus «tituli picti». Un santuario de época romana, Antigüedad y Cristianismo, IV, 1987, págs. 296-297. 
existencia del balneario termal, pero la comprobación de la existencia del yacimiento y de tal tipo de yacimiento hace el argumento más fuerte. $Y$ seguimos pensando en que el nombre de Fortuna hay que ponerlo en relación con una Fortuna Balnearis.

\section{X.2. Las ninfas y su culto en la Cueva}

En los epígrafes leídos aparecen aludidas las Ninfas en tituli repetidos e implícitamente bajo la designación de Latices Paphi. En la campaña de 1990 apareció una lucerna del tipo Bailey B grupo II, que es el mejor comentario a estas deidades: en el disco aparecen dos muchachas desnudas lavándose en una pila: el tema del agua y de los baños parece claro que fue ordinario en el ambiente y debió inspirar a los poetas del lugar sagrado.

\section{X.3. La mención a Asclepio}

Sin negar el problema del sincretismo con los matices tan sabiamente expuestos por nuestros colegas ${ }^{33}$, la relación del dios de la salud con el contexto balneario es tan obvia que no podia faltar.

\section{X.4. Los tiempos y los modos de culto}

No sabemos nada o conocemos indicios mínimos de los cultos existentes en los balnearios en la Antigüedad Clásica, fuera de los asclepieos. Pero no nos extraña la aparición de la fecha del 27 de marzo en nuestra cueva ya que la lavatio de Atis es algo que habria que adivinar si de adivinar se tratara en un ambiente de aguas termales. Las hipótesis formuladas para explicar la aparición y el sentido del culto a los dioses frigios en la Cueva Negra tendrá más consistencia si el contexto arqueológico de la Cueva es el balneario.

De igual manera y teniendo en cuenta que en el mundo romano los baños termales han dado origen a una arquitectura noble en la mayor

\footnotetext{
${ }^{33}$ MAYER, M., «La pervivencia de cultos púnicos: el documento de la Cueva Negra (Fortuna, Murcia)", L'Africa romana. Atti del VIl convegno di studio. Sassari, 15-17 diciembre 1989. Sassari 1990, págs. 695-702.
} 
parte de los casos y ello supone la asistencia de lo más selecto de la sociedad romana y latinizada, no nos extraña el florecimiento de un culto literario de relieve. No sabemos en qué medida tal culto se generalizó, pero donde se da, como es el caso de Fortuna, no causa extrañeza.

En una palabra, todo el elemento cultural existente en la Cueva Negra queda muy iluminado y muy potenciado por la contextualización de la Cueva en el ámbito de un balneario termal. El aspecto sobrenatural del calor de la tierra en las concepciones antiguas, su relación con las divinidades sobre todo salutiferas y los «prodigios» o simplemente los casos de curación obtenidos por los efectos del agua minero-termal han debido potenciar el contenido de la religión y sus manifestaciones en la zona. El avance de la investigación irá mostrando como.

\section{RESUMEN}

Se expone el estado de la cuestión en el estudio del termalismo de la Región de Murcia con particular atención a la época romana. Se centra el tema en la investigación del balneario de Fortuna y en las nuevas perspectivas que para el tema ha ofrecido el descubrimiento de una parte interesante del yacimiento romano del lugar cuyas excavaciones se describen: se trata de un edificio de considerable entidad cuya estructura todavía apenas queda especificada, pero que se espera aclarar con el avance de las investigaciones arqueológicas. Se plantean los nuevos horizontes que este descubrimiento crea para la interpretación del conjunto epigráfico de la Cueva Negra, cuyos tituli picti adquieren consistencia y se sitúan en una nueva dimensión intelectual al ponerlos en relación con la vida del balneario.

ABSTRACT

The situation of the research on thermalism in the Region of Murcia, with particular attention paid to the Roman period, are set forth in this article. The exposition centers on the research carried out in the baths of Fortuna and on the new perspectives opened by the discovery, in the Roman part of the site, of a large building which structure only dates partly 
determined. The authors explain the new horizon which this discovery offers towards the interpretation of the epigraphical collection found in the Cueva Negra, whose tituli picti acquire consistency and they are situated in a new intelectual dimension when they are related to the livelihood of the Roman Baths. 